Canadian

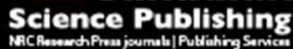

Canadian Geotechnical Journal Revue canadienne de géotechnique

\title{
Pore pressures induced by piezocone penetration
}

\begin{tabular}{|r|l|}
\hline Journal: & Canadian Geotechnical Journal \\
\hline Manuscript ID & cgj-2015-0206.R1 \\
\hline Danuscript Type: & Article \\
\hline Complete List of Authors: & $\begin{array}{l}\text { Chai, Jin; Saga University, } \\
\text { Hossain, Md. Julfikar; KUET, } \\
\text { Yuan, Dajun; Beijing Jiao Tong University and Tunnel and Underground } \\
\text { Engineering Research Center, Ministry of Education, School of Civil } \\
\text { Engineering } \\
\text { Shen, Shuilong; Shanghai Jiao Tong University, Department of Civil } \\
\text { Engineering; } \\
\text { Carter, John; University of Newcastle, }\end{array}$ \\
\hline Keyword: & $\begin{array}{l}\text { Piezocone test, Excess pore pressure, Coefficient of consolidation, } \\
\text { Numerical analysis }\end{array}$ \\
\hline \multicolumn{2}{|c}{} \\
\hline
\end{tabular}

\section{SCHOLARONE ${ }^{\text {m }}$}

Manuscripts 


\title{
Pore pressures induced by piezocone penetration
}

\author{
Jin-chun Chai \\ Saga University, Japan \\ E-mail: chai@cc.saga-u.ac.jp \\ Md. Julfikar Hossain \\ Khulna University of Engineering and Technology, Bangladesh
}

\section{Da-Jun Yuan}

School of Civil Engineering, Beijing Jiao Tong University and Tunnel and Underground Engineering Research Center, Ministry of Education, Beijing 100044, China

E-mail: yuandj603@163.com

\author{
Shui-long Shen \\ Department of Civil Engineering and State Key Laboratory of Ocean Engineering, Shanghai \\ Jiao Tong University, Shanghai 200240, China \\ Email: slshen@sjtu.edu.cn \\ John P. Carter \\ Faculty of Engineering and Built Environment, The University of Newcastle \\ NSW 2308, Australia \\ E-mail: John.Carter@newcastle.edu.au
}

\begin{abstract}
The excess pore water pressures $(u)$ induced by piezocone penetration and their dissipation around the cone have been investigated by laboratory model tests and theoretical/numerical analyses. Based on the test results, a method for predicting the cone penetration induced distribution of $u$ has been proposed. By numerical analysis using the predicted initial distribution of $u$ it has been demonstrated that dissipation of the pore water pressure measured at the shoulder of the cone ( $u_{2}$-type cone) is a two-dimensional (horizontal radial and vertical) process. By comparing the simulated and laboratory-measured 2D dissipation curves, a back-fitted coefficient of consolidation in the horizontal direction $\left(c_{h}\right)$ can be obtained. It has also been shown that a published method for estimating $c_{h}$ from measured non-standard dissipation curves (in which $u_{2}$ increases initially and then reduces) results in values of $c_{h}$ that agree well with values of $c_{h}$ deduced from the $2 \mathrm{D}$ analysis.
\end{abstract}

Keywords: Piezocone test, Excess pore pressure, Coefficient of consolidation, Numerical analysis 


\section{INTRODUCTION}

The piezocone is widely used as an in situ site investigation tool. Piezocone tests consist of a penetration phase and then a dissipation test conducted by holding the cone penetrometer at a pre-determined depth. The penetration test can provide continuous measurements of tip resistance $\left(q_{t}\right)$, skin friction $\left(f_{s}\right)$ and pore water pressure $(u)$, thus providing their variations with depth. Normally, the filter for pore pressure measurement is located at the shoulder of the cone, and the measured pore water pressure is designated as $u_{2}$. The outcome of the dissipation test is a dissipation curve of $u_{2}$, which can be used to determine the coefficient of consolidation in the horizontal direction $\left(c_{h}\right)$ of the soil stratum at the test depth. Numerous research studies have been published on this aspect of piezocone testing (Teh and Houlsby 1991; Chai et al. 2012a; 2014; Ansari et al. 2014; Mahmoodzadeh et al. 2014; Ha et al. 2015; Krage et al. 2015). There are also researches on using dissipation test results to estimate the undrained shear strength of the deposit (Mantaras et al. 2015)

Two types of piezocone dissipation curves have been reported in the literature. One displays monotonic reduction of the measured values of $u_{2}$ with time (e.g., Teh and Houlsby 1991), i.e., the so called "standard" dissipation curve; and the other is a "non-standard" curve, for which the measured value of $u_{2}$ increases initially and then reduces with time (Burns and Mayne 1998; Sully et al. 1999; Chai et al. 2012a; 2014; Ha et al. 2015). Some results of numerical simulation (e.g., Chai et al. 2012a) and laboratory testing (Kim et al. 2007; Chai et al. 2014) have suggested that the reason for a non-standard dissipation curve is that at the beginning of the dissipation the pore water pressure at the filter element induced by cone penetration is lower than the pore pressures generated in the soil nearby. The causes of this kind of initial pore water pressure distribution are thought to be: (1) the shear-induced dilatancy effect (e.g., Burns and Mayne 1998) and (2) the partial unloading effect when a soil element moves from the face to the shoulder of the cone during cone penetration (Chai et al. 
2012a).

All laboratory test results published to date regarding the distribution of $u$ around the cone only address the variation of $u$ in the horizontal (radial) direction at the elevation of the shoulder of a cone. To the best of the authors' knowledge, there are no measured data published about the variation in $u$ in the vertical direction in the soil around a cone. However, any variation of $u$ in the vertical direction is likely to have a considerable effect on the dissipation process of $u_{2}$. Cylindrical cavity expansion theory is widely used to predict the variation in $u$ in the horizontal (radial) direction around a cone (e.g., Randolph et al. 1979; Clarke et al. 1979; Chai et al. 2014). To date, no theoretical solution has been proposed for the variation in $u$ in the vertical direction. As a result, most dissipation analyses have been conducted considering only radial drainage. Understanding the variation of $u$ both in the radial and vertical directions is an important issue for understanding the dissipation behavior of $u_{2}$. It can also lead to increased accuracy of the value of $c_{h}$ estimated from piezocone dissipation tests, and therefore, further research on this aspect is needed.

In this study, laboratory model tests of piezocone penetration and dissipation were conducted. Pore water pressure measurements were made at the shoulder of the cone and at seven (7) distinct points in the soil around the cone. Based on the results of laboratory measurements and analysis, a method for predicting the excess pore water pressure distribution $(u)$ around the cone induced by piezocone penetration is proposed. Then both one-dimensional (1D, radial) and two-dimensional (2D, radial and vertical) dissipation analyses are conducted using the finite difference method, and the results are compared with each other and with the laboratory test results. Finally, using the results of 2D numerical analysis, the validity of an existing method for estimating the value of $c_{h}$ from piezocone dissipation curve is investigated, and discussion and recommendations are made.

\section{LABORATORY MODEL TESTS}

\subsection{Equipment}


The device and test procedure adopted in this study are basically the same as reported by Chai et al. (2014) and a brief description is given here including those parts changed or modified since the earlier study. A sketch of the test set-up is shown in Fig. 1. The cylindrical containment chamber is made of PVC and has an inner diameter of $0.485 \mathrm{~m}$ and a height of $1.0 \mathrm{~m}$. A piston system driven by air pressure was used to apply consolidation pressure to the top of the soil sample. To reduce the boundary effect, a smaller mini-piezocone with a diameter of $20 \mathrm{~mm}$ (in the previous study, the cone used had a diameter of $30 \mathrm{~mm}$ (Chai et al. 2014)) and a cone tip angle of $60^{\circ}$ was used in this study. The filter for pore water pressure measurement was installed on the shoulder of the cone. The penetration system consists of a reaction frame, a motor and a speed control unit. The penetration rate adopted was $25 \mathrm{~mm} / \mathrm{min}$, and it is $50 \%$ of the maximum penetration rate of the system. Although this rate is lower than that adopted in the standard field test, i.e., 20 $\mathrm{mm} / \mathrm{s}$, Kim et al. (2008) reported that for a saturated clayey soil and when the penetration rates are about $0.1 \mathrm{~mm} / \mathrm{s}$ to $20 \mathrm{~mm} / \mathrm{s}$, there is no obvious effect on the measured penetration tip resistance and the generated pore water pressure.

Seven (7) piezometers (Fig. 1 (a)) with a diameter of $20 \mathrm{~mm}$ and length of $25 \mathrm{~mm}$ were imbedded in the model ground at different radial distances and depths around the cone to monitor the pore water pressure distribution and its variation during the piezocone penetration and dissipation tests. The plan locations of $P_{1}$ to $P_{6}$ are illustrated in Fig. 1(b). In the figure, $r_{1}=(3$ to 4$) \cdot r_{0}$ (where $r_{0}$ is the radius of the cone); $r_{2}=(6$ to 7$) \cdot r_{0}$, and $r_{3}=9 \cdot r_{0}$. During piezocone penetration and the subsequent dissipation process, the pore water pressures at the shoulder of the cone and at the locations of the 7 piezometers installed in the model ground were monitored using a computer through a data logger.

\subsection{Test procedure}

\subsubsection{Preparation of model ground}

Three (3) layers of non-woven geotextile (about $138 \mathrm{~g} / \mathrm{m}^{2}$ ) were first placed at the 
bottom of the cylindrical chamber to act as a drainage layer. Then six (6) $0.1 \mathrm{~m}$ wide geotextile strips were lined vertically along the inner periphery of the chamber to facilitate drainage by outward radial flow of the pore water. Thoroughly remolded clay soil with an initial water content about 1.2 times its liquid limit was placed in the chamber layer by layer to a total thickness of about $0.8 \mathrm{~m}$. Seven (7) piezometers were installed when the thickness of the soil in the model reached the pre-determined levels. Finally, three layers of non-woven geotextile were placed on the top of the cylindrical soil specimen to act as a drainage layer, and the piston and air-pressure system were setup. A pre-determined air pressure was applied to pre-consolidate the model ground. Once the degree of pre-consolidation was more than $90 \%$ (judged from the measured settlement versus logarithm of time plot), the air-pressure was adjusted to result in a specimen with the desired over-consolidation ratio (OCR).

\subsubsection{Piezocone penetration and dissipation test}

After pre-consolidation, the thickness of the model ground was about $0.60 \mathrm{~m}$, and it is estimated that piezometers $P_{1}, P_{2}$ and $P_{3}$ were then located about $0.3 \mathrm{~m}$ below the surface of the model ground. The piezocone was then penetrated into the sample so that the pore pressure filter at the shoulder of the cone was located at a depth of $0.3 \mathrm{~m}$ from the surface of the model ground. A dissipation test was then conducted by holding the cone stationary.

\subsection{Materials used and cases tested}

Two types of soils were used. One was remoulded Ariake clay (Miura et al. 1998) and the other was a mixture composed of river sand passing the $2 \mathrm{~mm}$ sieve and Ariake clay, with a ratio of sand/clay of 60:40 by dry weight. The physical properties of these soils are listed in Table 1. The initial water content of the Ariake clay was adjusted to about $133.0 \%$ and for the mixed soil it was about $53.1 \%$. For both soils, the initial water content was about 1.2 times the corresponding liquid limit.

Cases tested and the conditions adopted are summarized in Table 2. For all cases, after 
the penetration and dissipation test, soil samples from the model ground were taken for odometer testing and laboratory mini vane (diameter of $20 \mathrm{~mm}$ and height of $40 \mathrm{~mm}$ ) shear tests. The shearing speed adopted was 6 degrees/min. This speed is the same as suggested for a field vane shear test by the Japanese Geotechnical Society (JGS 2009). Although the vane used in the laboratory is usually smaller than that used in the field, in Japan, most laboratory vane shear tests adopt this shear speed.

In order to predict the cone penetration induced excess pore water pressure distribution around the cone using cavity expansion theory, the values of the rigidity index $\left(I_{\mathrm{r}}\right)$ and the undrained shear strength $\left(s_{u}\right)$ of the soil are needed. $I_{r}$ is the ratio between the shear modulus and shear strength.

It has been reported that $I_{r}$ reduces with OCR (Mayne 2001; Krage et al. 2014). Kulhawy and Mayne (1990) proposed a method based on Cam clay theory to predict the relationship between $I_{r}$ and OCR as follows.

$$
I_{r}=\frac{2 \cdot M\left(1+e_{0}\right)}{3 \lambda} \frac{[1+\ln (O C R)] \exp (\Lambda)}{\Lambda(1-\Lambda) O C R^{\Lambda}}
$$

where $\Lambda=1-\kappa / \lambda, \lambda=$ slope of consolidation line in an $e-\ln p^{\prime}$ plot ( $e$ is voids ratio and $p^{\prime}$ is effective mean stress); $\kappa=$ slope of rebound line in an $e-\ln p^{\prime}$ plot; $M=$ strength parameter for the Cam-clay model, which is the stress ratio, $q / p^{\prime}$, at failure, ( $q$ is deviator stress); $e_{0}=$ initial void ratio. Assuming $\Lambda=0.9$, for $\mathrm{OCR}=8$, the predicted value of $I_{r}$ is about $48 \%$ of the value for $\mathrm{OCR}=1$

However, Kim et al. (2007) reported the results of some large-scale model test (diameter of the mold used was $1.2 \mathrm{~m}$ ) involving piezocone penetration. The measured excess pore water pressure $(u)$ distribution indicated that the diameter of the zone with an increase in $u$ (assumed to be the plastic zone) is almost the same for cases of OCR from 1 to 20 . In the theory of cavity expansion, the diameter of the plastic zone varies as the square root of $I_{r}$, and therefore the results of these tests indirectly indicate that $I_{r}$ may, in fact, not reduce 
significantly with OCR. The results of the laboratory model tests conducted in this study indicate the same tendency.

For field conditions, or in a laboratory model test, OCR is defined as the ratio of vertical effective yield stress $\left(p_{c}\right)$, assumed to be the past maximum vertical effective stress sustained by the soil, over the current vertical effective stress $\left(\sigma_{v 0}^{\prime}\right)$. For an over-consolidated soil, the coefficient of earth pressure at-rest $\left(K_{0}\right)$ is larger than that at a normally consolidated state (Mayne and Kulhawy 1982). For a cone penetration problem, the larger value of $K_{0}$ at higher values of OCR will have a considerable effect on the mobilized value of $I_{r}$, because the dominant cone penetration induced deformation is in the horizontal direction. And the stress and strain paths experienced by the soil surrounding a cone during the cone penetration process may be different from that of laboratory triaxial and/or simple shear tests. Therefore, in this study it has been assumed that $I_{r}$ will increase with consolidation stress (confinement) but it will not change with OCR.

Based on back analyzed results, for reconstituted Ariake clay under about $100 \mathrm{kPa}$ vertical consolidation pressure, it has been shown that the value of $I_{r}$ is about 100 (Chai et al. 2014). Referring to this information the values of $I_{r}$ for the reconstituted Ariake clay model ground samples have been assumed as 60 to 120 , corresponding to vertical consolidation pressure of 48 to $192 \mathrm{kPa}$. This range corresponds to soft to medium stiff clays (Vesic 1972). For the cases involving the mixed soil, the assumed values of $I_{r}$ are approximately 20 more than for the corresponding case of the Ariake clay. The adopted values of $I_{r}$ are listed in Table 2. However, for test Case 4 in Table 2, one analysis was conducted with a reduced value of $I_{r}\left(I_{r}=60\right)$, and the simulated initial distribution of the excess pore water pressure is compared with the measured data to show the effect of $I_{r}$ on the cone penetration induced $u$ distribution.

The values of $s_{u}$ of the model ground samples were measured by the laboratory mini-vane shear test. However, the initial total stress applied mechanically to the samples used for the mini-vane shear tests was close to zero, which is different from the stress condition in the 
model ground immediately prior to cone penetration. Considering this factor, values of $s_{u}$ were estimated using Ladd (1991)'s equation

$$
s_{u}=S \cdot \sigma_{v}^{\prime} \cdot(O C R)^{m}
$$

where $\sigma_{\mathrm{v}}^{\prime}=$ vertical effective stress; and $S$ and $m$ are constants. Ladd's suggested value of $m$ $=0.85$ was adopted. Then, assuming that the suction pressure in the samples for the mini-vane shear test was about $10 \mathrm{kPa}, S=0.31$ was evaluated for both the reconstituted Ariake clay and the mixed soil. The estimated values of $s_{u}$ are also listed in Table 2 .

\section{EXCESS PORE PRESSURE DISTRIBUTION AND DISSIPATION ANALYSIS}

\subsection{Initial excess pore water pressure distribution $(u)$}

As illustrated in Fig. 2, by approximating the cone penetrometer as a cylinder on top of a half sphere, the process of cone penetration can be approximated as cylindrical and spherical cavity expansions (Vesic 1972) for the zone above and below the shoulder of the cone, respectively. If the soil is idealized as a linear elastic, perfectly plastic solid with a constant shear strength $s_{u}$ deforming under undrained (constant volume) conditions, then the following well-known expressions for pore water pressure generated by cavity expansion may be derived.

(1) Excess pore pressure $\left(\Delta u_{c y}\right)$ induced by a cylindrical cavity expansion:

$$
\begin{aligned}
\Delta u_{c y} & =2 s_{u} \ln \left(\frac{R_{c y}}{r}\right) \\
\frac{R_{c y}}{r_{0}} & =\sqrt{I_{r}}
\end{aligned}
$$

where $r$ horizontal radial distance, $R_{c y}=$ radius of plastic zone around an expanding cylindrical cavity, and $r_{0}=$ radius of the cone (or cavity).

(2) Excess pore water pressure $\left(\Delta u_{s p}\right)$ induced by a spherical cavity expansion

$$
\Delta u_{s p}=4 s_{u} \ln \left(\frac{R_{s p}}{r_{3}}\right)
$$




$$
\frac{R_{s p}}{r_{0}}=\sqrt[3]{I_{r}}
$$

where $R_{s p}=$ radius of plastic zone around an expanding spherical cavity, and $r_{3}=$ spherical radial distance.

(3) Values of excess pore water pressure $(u)$ in different zones

As shown in Fig. 3, for Zones A and B around the shaft and the face of the cone, there will be considerable additional shear deformation of the soil (e.g., vertical shearing adjacent to the shaft) which will induce additional excess pore water pressure increments. In Zone A, when soil elements are moving from the face to the shoulder/shaft of the cone, there may also be a partial unloading effect (Chai et al. 2012a).

\section{(a) Zone A}

The value of $\Delta u$ in Zone A includes three parts, i.e., components induced by cylindrical cavity expansion $\left(\Delta u_{c y}\right)$ as calculated by Eq. (3), further shear deformation $\left(\Delta u_{s}\right)$ and partial unloading $\left(\Delta u_{u l}\right)$, and can be expressed as:

$$
\Delta u=\Delta u_{c y}+\Delta u_{s}+\Delta u_{u l}
$$

Using the Modified Cam Clay (MCC) model (Roscoe and Burland 1968) and assuming an undrained compression stress path, the maximum shear-induced excess pore water pressure, $\left(\Delta u_{s}\right)_{m}$, can be expressed as (Randolph et al. 1979):

$$
\left(\Delta u_{s}\right)_{m}=p_{i}^{\prime}-p_{f}^{\prime}
$$

where $p_{i}^{\prime}$ and $p_{f}^{\prime}=$ the values of mean effective stresses in the soil initially and at failure (on the critical state line), respectively. Further, using the MCC model and considering an undrained compression stress path, $p_{f}^{\prime}$ can be predicted as follows:

$$
p_{f}^{\prime}=\frac{p_{i}^{\prime}}{2^{\Lambda}}\left(\frac{M^{2}+\eta_{i}^{2}}{M^{2}}\right)^{\Lambda}(O C R)^{\Lambda}
$$

Where $\eta_{i}=q_{i} / p_{i}^{\prime}\left(q_{i}\right.$ is the initial deviator stress. In order to calculate $q_{i}$ and $p_{i}^{\prime}$ for field 
conditions, the coefficient of at-rest earth pressure $\left(K_{0}\right)$ can be estimated by Mayne and Kulhawy's (1982) equation:

$$
K_{0}=\left(1-\sin \left(\phi^{\prime}\right)\right)(O C R)^{\sin \left(\phi^{\prime}\right)}
$$

where $\phi \phi=$ effective friction angle of the soil. Calculating $\left(\Delta u_{s}\right)_{m}$ by Eqs (8) and (9) implies that the undrained shear strength, $s_{u}$, can be calculated from the MCC model, and the relationship between $s_{u}$ and $p_{f}^{\prime}$ is:

$$
p_{f}^{\prime}=c s \cdot s_{u} / M
$$

where $c s=2$ for triaxial stress conditions and $\sqrt{3}$ for plane strain stress conditions (Randolph et al. 1979). Shear strains will generally reduce with radial distance from the cone. It is therefore assumed that when the radial distance is larger than $r_{s}$, the shear induced excess pore water pressure can be ignored, and the value of $r_{s}$ can be expressed as (Chai et al. 2014):

$$
r_{s}=m_{1} \cdot(O C R)^{n_{1}} \cdot R_{c y} \quad\left(r_{s} \geq r_{0}+5(\mathrm{~mm})\right)
$$

where $m_{1}$ and $n_{1}=$ constants, and the suggested values are $m_{1}=0.15$ and $n_{1}=0.1$ (Chai et al. 2014).

Regarding the variation of $\Delta u_{s}$ with radial distance, it is assumed that $\Delta u_{s}$ has a maximum value at $r=r_{0}$, and zero at $r=r_{s}$, but it varies with $1 / r$. In this case $\Delta u_{s}$ can be expressed as:

$$
\Delta u_{s}=\left(p_{i}^{\prime}-p_{f}^{\prime}\right) \frac{r_{0}}{r_{s}-r_{0}}\left(\frac{r_{s}}{r}-1\right) \quad\left(r_{s} \geq \mathrm{r} \geq r_{0}\right)
$$

As for the value of $\Delta u_{u l}$, designate the absolute maximum value of $\Delta u_{u l}$ induced by the partial unloading as $\left(\Delta u_{u l}\right)_{\mathrm{m}}$, and then assuming $\left(\Delta u_{u l}\right)_{\mathrm{m}}$ is a portion of the cavity expansion induced value of $u$ at $r=r_{0}$, the following empirical equation (Chai et al. 2014) can be used for calculating $\Delta u_{u l}$

$$
\Delta u_{u l}=-m \cdot\left(\Delta u_{c y}\right)_{r=r_{0}} \cdot(O C R)^{n} \frac{r_{0}}{r_{s}-r_{0}}\left(\frac{r_{s}}{r}-1\right)
$$


where $m$ and $n=$ constants. The suggested values are: $m=0.2$ and $n=0.25$.

\section{(b) Zone B}

In Zone $\mathrm{B}$, the effect of shear deformation on $u$ also needs to be considered. It is simply assumed that $\Delta u_{s}$ calculated by Eq. (12) at $r=r_{0}$ varies linearly with the angle $\alpha$ (see Fig. 3) around the surface of the cone and becomes zero at $\alpha=\pi / 2$ (tip of the cone). In Fig. $3, r_{s 3}$ also reduces with $\alpha$ and becomes $r_{0}$ at $\alpha=\pi / 2$, i.e.,

$$
r_{s 3}=r_{0}+\left(r_{s}-r_{0}\right)(1-2 \alpha / \pi)
$$

Replacing $r_{s}$ in Eq. (13) by $r_{s 3}$, and multiplying $\left(p^{\prime}{ }_{i}-p_{f}^{\prime}\right)$ by $(1-2 \alpha / \pi)$ (Eq. 8$)$ provides:

$$
\Delta u_{s}\left(\alpha, r_{3}\right)=\left(p_{i}^{\prime}-p_{f}^{\prime}\right) \frac{r_{0}}{r_{s}-r_{0}}\left(\frac{r_{s 3}}{r_{3}}-1\right) \quad\left(r_{3} \leq r_{s 3}\right)
$$

(c) Zones C and D

In Zones $\mathrm{C}$ and $\mathrm{D}$, values of $u$ can be calculated by cylindrical or spherical cavity expansion theories (Eq. (3) or Eq. (5)), respectively.

(4) Discontinuity in $u$ along $A_{1}-A_{2}$ (Fig. 2)

From Eqs (2) to (5), for given values of $I_{r}$ and $s_{u}, R_{c y}>R_{s p}$, and at $r=r_{3}=r_{0}, \Delta u_{c y}<\Delta u_{s p}$. Therefore, along the line $A_{1}-A_{2}$ in Fig. 2, the values of $u$ calculated by the cylindrical and spherical cavity expansion theories are different. To avoid computational difficulties in the subsequent numerical analysis of the pore water pressure dissipation process, it was simply assumed that the average values of the two theories may be adopted as a reasonable approximation of the initial excess pore water pressure along the line $A_{1}-A_{2}$.

\subsection{Dissipation analysis}

(1) Consolidation theory

The governing equation for axisymmetric (2D) pore pressure dissipation is as follows:

$$
c_{h}\left(\frac{\partial^{2} u}{\partial r^{2}}+\frac{\partial u}{r \cdot \partial r}\right)+c_{v} \frac{\partial^{2} u}{\partial z^{2}}=\frac{\partial u}{\partial t}
$$

where: $r=$ horizontal radial distance; $z=$ vertical distance; $t=$ time; and $c_{h}$ and $c_{v}=$ 
coefficients of consolidation in the horizontal and vertical directions respectively.

The 2D dissipation analysis model with drainage boundary conditions is shown in Fig. 4. For simulating the laboratory model tests the outer radial distance adopted was $0.243 \mathrm{~m}$ and the vertical range was $0.3 \mathrm{~m}$, measured from the top 'undrained' (impermeable) boundary to the bottom 'drained' (drainage) boundary in (Fig. 4). The cone itself was modeled as an impermeable body and the initial distribution of $u$ was generated by the method described in the previous section. Governing equation (17), of the uncoupled consolidation theory (Terzaghi-Rendulic type), was solved by the finite different method.

The main purposes of the dissipation analysis are: (1) to investigate the effect of drainage in the vertical direction on the dissipation of the pore water pressure $\left(u_{2}\right)$ at the shoulder of the cone; and (2) to back-fit the coefficients of consolidation of the soil samples used in the laboratory testing. The back-fitting has been carried out by visually comparing the laboratory measured and simulated dissipation curves, and adopting a value of $c_{h}$ that results in the "best" match to the measured curve. This value is designated as the "back fitted" value of $c_{h}$. It is noted that even reconstituted clayey soil samples subjected to one-dimensional consolidation exhibit stress induced anisotropic consolidation behavior (Chai et al. 2012b; 2015; Aiga 2015). For example, for reconstituted Ariake clay constrained horizontally and subjected to a vertical consolidation pressure, $p^{\prime}>20 \mathrm{kPa}$, the coefficient of consolidation in the horizontal direction $\left(c_{h}\right)$ is about 1.5 times of the value in the vertical direction $\left(c_{v}\right)$, i.e., $c_{h} / c_{v} \approx 1.5$ (Aiga 2015). In back fitting the value of $c_{h}$ from the measured dissipation curves using 2D dissipation analysis, the anisotropic consolidation behavior of the model ground was considered. Based on the laboratory test results of Aiga (2015), in cases where the model ground was made of the Ariake clay, $c_{h} / c_{v}=1.5$ was fixed during the back-fitting process. In the case of the mixed soil, since $60 \%$ of the soil mass was sand, for which anisotropic consolidation behavior is considered to be negligible, $c_{h}=c_{v}$ was adopted.

For the numerical model adopted, the distance $\left(Z_{0}\right)$ from the shoulder of the cone to the 
top impermeable ("undrained") boundary (Fig. 4) will have an effect on predictions of the vertical dissipation process. In field or laboratory model test conditions, vertical drainage can actually occur in both the upward and downward directions. So the top impermeable boundary shown in Fig. 4 is considered to be an artificial dividing line, above which $u$ dissipates by upward flow of pore water and below which it dissipates by downward flow. Considering the filter at the shoulder of a cone, the larger the value of $Z_{0}$, the slower will be the rate of dissipation observed at the shoulder. Using parameters applicable to the Case 4 model test and the back-fitted value of $c_{h}$, the simulated dissipation curves corresponding to $Z_{0}=2 r_{0}$ and $4 r_{0}$ are plotted and compared in Fig. 5. By comparing these predictions with the measured data, a value of $Z_{0}=4 r_{0}$ has been adopted as suitable for the subsequent cases considered in this study.

For the purpose of comparison, dissipation analyses only considering the horizontal radial drainage (1D) at the elevation of the shoulder of the cone (filter element location) were also conducted. These comparisons are considered in the following section.

\section{MEASURED AND SIMULATED RESULTS}

\subsection{Excess pore water pressure distribution $(u)$}

The model test Case 4 had a value of OCR of 8 . If the reduction of the value of $I_{r}$ given by Eq. (1) is considered, the value of $I_{r}$ for Case 4 will be about half of that for Case $1(\mathrm{OCR}=1)$. For Case 4, two analyses were conducted using $I_{r}$ of 120 and 60 respectively, and the simulated initial distributions of $u$ in the horizontal radial direction are compared in Fig. 6 together with the measured data. It can be seen that the results for $I_{r}=120$ agree well with the measurements; while the case of $I_{r}=60$ resulted in a smaller plastic zone and smaller values of $u$ than the measurements. All the analyzed results presented below were obtained using the values of $I_{r}$ listed in Table 2 .

For the model test Case 4, the measured and simulated distributions of $u$ obtained using the back-fitted value of $c_{h}$ (with fixed ratio of $c_{h} / c_{v}=1.5$ ) at elapsed times of $t=0 ; 60$ min. 
and 240 min. are shown in Figs. 7(a) to (c) and 8(a) to (c), respectively. Since the measuring points were limited, the measurements did not capture the higher values of $u$ around the face and the shoulder of the cone. However, both the measured and simulated initial distributions (Fig. 7(a) and Fig. 8(a)) show that: (1) the spherical zone of influence around the tip of the cone is smaller than the cylindrical zone of influence around the shaft of the cone; and (2) above the filter location (at the shoulder), the variation of $u$ in the vertical direction is small and close to the results predicted from the cylindrical cavity expansion theory. These two points support the assumptions adopted for predicting the cone penetration induced distribution of $u$. At $t=60 \mathrm{~min}$. and $240 \mathrm{~min}$., the simulated distributions of $u$ are quantitatively comparable with the measured ones. However, there are some discrepancies and it is considered that these are most likely due to the boundary effects of the model adopted. This issue will be discussed in the following section.

\subsection{Dissipation curves}

(a) Dissipation curve of $u_{2}$

The measured and simulated dissipation curves of $u_{2}$ are compared in Fig. 9. Firstly, it can be seen that using the back-fitted value of $c_{h}$, the $2 \mathrm{D}$ simulation compares well with the measured curve for elapsed times larger than about $0.5 \mathrm{hr}$. Comparing the $1 \mathrm{D}$ and $2 \mathrm{D}$ simulations obtained with the same value of $c_{h}$ indicates that vertical drainage (2D) increases the rate of dissipation of $u_{2}$.

(b) Dissipation curves at $P_{1}, P_{2}$ and $P_{3}$

Comparisons of the simulated and measured dissipation curves are given in Figs. 10 (a) to (c) for locations $P_{1}, P_{2}$ and $P_{3}$, respectively. Due to the effect of the vertical drainage, 2D simulation resulted in smaller peak values of $u$ and faster dissipation rates. When comparing the predictions with the measured data, the fact that boundary effects were significant in the laboratory tests needs to be considered. $\quad P_{1}$ was located away from the vertical boundary (the wall of the chamber), and 2D simulation agrees well with the measured data for $t>0.2 \mathrm{hr}$. 
For $P_{2}$ and $P_{3}$, there are obvious differences in both the peak value of $u$ and the dissipation process between the measured and simulated results. It is considered most likely this discrepancy is due to the boundary (wall of the chamber and the "rigid" piston on top of the model ground) effects, which are elaborated as follows.

During installation of the penetrometer, the model ground will deform under close to undrained conditions and the soil will tend to behave initially as an incompressible material. The volume occupied by the body of the cone must therefore be accommodated by upward movement (heave) of the loading piston. Such heave has been confirmed by the laboratory measured data, and for the cases tested the measured average heaving during the model cone penetration process was about $0.5 \mathrm{~mm}$. Furthermore, as the cone penetrates into the model ground the soil will also move radially, so that the lateral constraint on radial displacement caused by the wall of the chamber will tend to increase the peak values of $u$ at points near the wall. Further, the piston located at the top of the model ground is much stiffer than the soil. So the tendency for non-uniform vertical heaving of the soil around a penetrating cone will be suppressed, resulting in non-uniform contact pressure developing between the piston and the soil, i.e., it would be initially higher around the cone and lower around the inner periphery of the containment chamber. With the increase of elapsed time, the contact pressure will tend to become more uniform, which may cause $u$ to increase at the locations $P_{2}$ and $P_{3}$ during the earlier stages of the dissipation. Therefore, the measured dissipation curves at the locations $P_{2}$ and $P_{3}$ may not reflect accurately the fundamental behavior of soil in a field piezocone test, particularly the excess pore pressure induced by cone penetration and subsequent dissipation, but may be the result of the boundary effects described above.

(c) Dissipation curves at $P_{7}$

$P_{7}$ was located ahead of the cone tip, and only $2 \mathrm{D}$ analysis can simulate its dissipation curve. The comparison of the simulated and the measured curves is given in Fig. 11. It can be seen that the simulated pore water pressures agree well with the measured values. In 
particular, the rise and subsequent dissipation of the excess pore pressure is well captured by the $2 \mathrm{D}$ analysis. This result indirectly confirms the validity of the assumptions adopted to predict the cone penetration induced distribution of $u$ around the tip of the cone.

For completeness, the measured dissipation curves of the piezometers 4,5 and 6 in Case 4 are depicted in Fig. 12. Those piezometers were installed at a level of $200 \mathrm{~mm}$ above the tip of the cone (see Fig. 1 for illustration of the locations).

\section{EVALUATING $c_{h}$}

The primary purpose of piezocone dissipation tests is estimating a field value of the coefficient of consolidation of the soil strata in the horizontal direction $\left(c_{h}\right)$. Various approximate methods have been proposed for this estimation (e.g., Burns and Mayne 1998; Chai et al. 2012a; 2014).

One of the aims of predicting the distribution of excess pore pressure around a penetrating cone and then simulating the dissipation process is to provide a fundamental basis for evaluating the validity of any approximate methods proposed for estimating values of $c_{h}$ from measured piezocone dissipation curves. Assuming that the back-fitted value of $c_{h}$ described previously most likely represents the "true" value for the soil, the correctness or otherwise of existing methods for estimating the value of $c_{h}$ from dissipation curves can be evaluated.

(1) Estimating value of $c_{h}$ from the measured dissipation curve

For all model tests conducted, the measured dissipation curves are non-standard, i.e., initially $u_{2}$ increased and then it reduced. Chai et al. (2012a) proposed a method for estimating the value of $c_{h}$ from such non-standard dissipation curves. The basic idea of this method is to correct the measured time taken for the excess pore water pressure to dissipate from its maximum value to $50 \%$ of the maximum value, $t_{50}$. The corrected time is defined as $t_{50 \mathrm{c}}$, and then this value of $t_{50 \mathrm{c}}$ is used in the equation proposed by Teh and Houlsby (1991) for standard dissipation curves to calculate directly the value of $c_{h}$. The equation proposed by 
Chai et al. (2012a) for evaluating $t_{50 \mathrm{c}}$ is as follows:

$$
t_{50 c}=\frac{t_{50}}{1+18.5 \cdot\left(\frac{t_{u \max }}{t_{50}}\right)^{0.67}\left(\frac{I_{r}}{200}\right)^{0.3}}
$$

where $t_{\text {umax }}=$ time period from the start of a dissipation test to when the measured value of $u_{2}$ reaches its maximum. For an $u_{2}$-type piezocone, the equation for calculating the value of $c_{h}$ is as follows:

$$
c_{h}=\frac{0.245 \cdot r_{0}^{2} \cdot \sqrt{I_{r}}}{t_{50 c}}
$$

(2) Comparison of back-fitted and estimated values of $c_{h}$

Applying Eqs (18) and (19) to the results of nine model dissipation tests (Table 2), values of $c_{h}$ have been estimated, and in Table 3 they are compared with: (a) numerically back-fitted values of $c_{h}$ from $1 \mathrm{D}$ and 2D analyses; and (b) values of the coefficient of consolidation of the soil in the vertical direction, $c_{v}$, measured directly in laboratory odometer tests corresponding to the appropriate initial vertical effective stress $\left(\sigma_{\mathrm{v} 0}^{\prime}\right)$.

Fig. 13 compares estimated values of $c_{h}$ and laboratory measured values of $c_{v}$. For the mixed soil, there are two (2) cases where the measured values of $c_{v}$ are higher than the estimated values of $c_{h}$ (the reason is not clear), and for the other four (4) cases, the data points are scattered around the 1:1 line in the plot. For the cases using Ariake clay, all values of $c_{v}$ are lower than the estimated values of $c_{h}$, and this is possibly due to the stress induced anisotropic consolidation behavior of the clayey soil $\left(c_{h}>c_{v}\right)$ (Chai et al. 2012b; 2015). Therefore, the results in Fig. 13 confirm the usefulness of Eqs (18) and (19) for estimating value of $c_{h}$ from piezocone dissipation test result.

Fig. 14 compares estimated and back-fitted values of $c_{h}$. It can be seen that the estimated values are very close to the values back-fitted from the $2 \mathrm{D}$ simulations, i.e., their relationship is close to the $1: 1$ line in the plot. If it is assumed that the back-fitted values from the 2D simulations represent the "true" values of this coefficient for the model ground, 
then the results in Fig. 14 indicate the high accuracy of the approximate method for estimating the value of $c_{h}$. The numerical results also indicate that it is possible to simulate the measured dissipation curves by 1D analysis (radial drainage only). While, the back-fitted values of $c_{h}$ from 1D analysis are on average about 1.6 times the estimated values, i.e., a larger value of $c_{h}$ is needed to indirectly include the effect of vertical drainage on the dissipation of $u_{2}$. The results in Fig. 14 clearly show that in back-fitting the value of $c_{h}$, an analysis involving only horizontal radial (1D) dissipation is not suitable for interpreting the results of an $u_{2}$-type cone.

\section{CONCLUSIONS}

The excess pore water pressures $(u)$ induced by piezocone penetration and their dissipation around the cone have been investigated by laboratory model tests and theoretical/numerical analyses. Based on the test and analysis results, the following conclusions can be drawn.

(1) The distribution of pore water pressure above the shoulder of the cone generated by cone penetration is close to that predicted by cylindrical cavity expansion theory, while around the tip of the cone it is close to that predicted by spherical cavity expansion theory. A more detailed method for predicting the distribution of pore water pressures around the cone has been proposed, which includes the effects of additional soil shearing and the transition of soil from the face to the shoulder of the cone. This more sophisticated approach formed the basis for further investigation of the behavior of the soil during piezocone dissipation tests.

(2) Using the predicted distribution of excess pore water pressure, both one-dimensional (radial) and two-dimensional (radial and vertical) dissipation analyses were conducted. It has been shown that for the pore water pressure measured at the shoulder of the cone (an $u_{2}$-type cone), the dissipation is closer to a $2 \mathrm{D}$ process rather than a $1 \mathrm{D}$ process.

(3) By comparing the 2D simulated dissipation curve with one measured in a laboratory model test, a back-fitted coefficient of consolidation $\left(c_{h}\right)$ in the horizontal direction was 
obtained. Values of $c_{h}$ were also estimated by an existing approximate method suggested for interpreting non-standard dissipation curves ( $u_{2}$ increasing initially and then reducing). Comparing the back-fitted and the estimated values of $c_{h}$ showed that the approximate estimation method results in accurate values of $c_{h}$.

\section{ACKNOWLEDGMENTS}

This work was partially funded by National Key Basic Research Program of China (973 Program: 2015CB057802).

\section{REFERENCES}

Aiga, K 2015. Effect of pore liquids on the properties of consolidation and micro-structures of Ariake clay. Thesis for Master of Engineering, Saga University, Japan.

Asari, Y, Merifield, R and Sheng, D 2014. A piezocone dissipation test interpretation method for hydraulic conductivity of soft clays. Soils and Foundations, 54(6): 1104-1116.

Burns, S. E., Mayne, PW 1998. Monotonic and dilatory pore pressure decay during piezocone tests in clay. Can Geotech J., 35(6): 1063-1073.

Chai, J-C, Sheng, D-C, Carter, JP, Zhu, H-H 2012a. Coefficient of consolidation from non-standard piezocone dissipation curves. Computers and Geotechnics; 41: 13-22.

Chai, J-C, Jia, R, Hino, T. 2012b. Anisotropic consolidation behavior of Ariake clay from three different CRS tests. Geotechnical Testing Journal ASTM; 35(6): 1-9.

Chai, J-C, Hossain, Md J, Carter, JP and Shen, S-L 2014. Cone penetration-induced pore pressure distribution and dissipation. Computers and Geotechnics, 57: 105-113.

Chai, J-C, Jia, R, Nie, J-X, Aiga, K, Negami, T and Hino, T 2015. 1D deformation induced permeability and microstructural anisotropy of Ariake clays. Geomechanics and Engineering, 8(1): 81-95.

Clarke, BG, Carter, JP and Wroth, CP 1979. In situ Determination of the Consolidation Characteristics of Saturated Clays. Proceedings 7 th European Conference on Soil Mechanics and Foundation Engineering, Brighton, British Geotechnical Society, London, 2: $207-211$. 
Ha, T-G, Jang, I-S, Choo, Y-S and Chung, C-K 2015. Evaluation of coefficient of consolidation for dilatory dissipation in piezocone test in overconsolidated cohesive soils. KSCE Journal of Civil Engineering, 18(2): 475-487.

Japanese Geotechnical Society (JGS) 2009. Site Investigation: Basic and manual. JGS, Tokyo, Japan, 135-140.

Kim, T, Kim, N, Tumay, MT, Lee, W 2007. Spatial distribution of excess pore-water pressure due to piezocone penetration in overconsolidated clay. Journal of Geotechnical and Geoenvironmental Engineering, 133(6): 674-683.

Kim, K, Prezzi, M, Salgado, R and Lee, W. 2008. Effect of penetration rate on cone penetration resistance in saturated clayey soils. Journal of Geotechnical and Geoenvironmental Engineering, 134(8): 1142-1153.

Krage, CP, Broussard, NS and DeJong, JT 2014. Estimating rigidity index $\left(I_{R}\right)$ based on CPT measurements. Proceedings of 3rd International Symposium on Cone Penetration Testing, Las Vegas, Nevada, 727-735.

Krage, CP, DeJong, JT and Schnaid, F 2015. Estimation of the coefficient of consolidation from incomplete cone penetration test dissipation tests. Journal of Geotechnical and Geoenvironmental Engineering, 141(2): Article number 06014016.

Kulhawy, FH and Mayne, PW 1990. Manual on estimating soil properties for foundation design. Report EL-6800. Electric Power Research Institute, Palo Alto, 306 p.

Ladd, CC 1991. Stability evaluation during staged construction. Journal of Geotechnical and Geoenvironmental Engineering ASCE, 117(4): 540-615.

Mahmoodzadeh, H, Randolph, MF and Wang, D 2014. Numerical simulation of piezocone dissipation test in clays. Geotechnique, 64(8): 657-666.

Mantaras, F. M., Odebrecht, E. and Schnaid, F. 2015. Using piezocone dissipation test to estimate the undrained shear strength in cohesive soil. Can. Geotech. J. 52: 318-325.

Mayne, PW 2001. Stress-strain-strength-flow parameters from enhanced in-situ tests. Proceedings of International Conference on In-Situ Measurement of Soil Properties \& 
Case Histories (In-Situ 2001), Bali, Indonesia, 47-69.

Mayne, PE and Kulhawy, FH 1982. K $0^{-} \mathrm{OCR}$ relationships in soils. J. of Geotech.Engrg., ASCE, 108(GT6): 851-872.

Miura, N, Chai, J-C, Hino, T, Shimoyama, S 1998. Depositional environment and geotechnical properties of Ariake clay. Indian Geotechnical Journal 1998, 28(2): 121-146.

Randolph, MF, Carter, JP, Wroth, CP 1979. Driven piles in clay - the effects of installation and subsequent consolidation. Geotechnique, 29(4): 361-93.

Roscoe, KH, Burland, JB 1968. On the generalized stress-strain behavior of wet clay. In: Engineering Plasticity (edited by J. Heyman and F.A. Leckie), Cambridge University Press, 535-609.

Sully, JP, Robertson, PK, Campanella, RG, Woeller, DJ 1999. An approach to evaluation of field CPTU dissipation data in overconsolidated fine-grained soils. Can Geotech J, 36: $369-381$.

Teh, CI, Houlsby, GT 1991. An analytical study of the cone penetration test in clay. Geotechnique , 41(1): 17-34.

Vesic, AS 1972. Expansion of cavities in infinite soil mass. Journal of Soil Mechanics and Foundation Engineering, ASCE, 98(SM3): 265-290. 


\section{List of figures}

Fig. 1 Schematic diagram of laboratory model test

(a) Illustration of the set-up of the test; (b) Plan view of the locations of piezometers $\left(P_{1}\right.$ to $\left.P_{6}\right)$

Fig. 2 Model for cone penetration induced ground deformation

Fig. 3 Zones around the cone

Fig. 4 Model for dissipation analysis

Fig. 5 Effect of $Z_{0}$ on the simulated dissipation curves

Fig. 6 Effect of $I_{r}$ on the initial $u$ distributions of Case 4

Fig. 7 Measured excess pore water pressure distributions (Case 4)

(a) $t=0 \mathrm{~min}$; (b) $t=60 \mathrm{~min}$; (c) $t=240 \mathrm{~min}$

Fig. 8 Predicted excess pore water pressure distributions (Case 4)

(a) $t=0 \mathrm{~min}$; (b) $t=60 \mathrm{~min}$; (c) $t=240 \mathrm{~min}$

Fig. 9 Comparison of dissipation curves at $u_{2}$ location

Fig. 10 Dissipation curves at locations $P_{1}, P_{2}$ and $P_{3}$

(a) At location $P_{1}$; (b) At location $P_{2}$; (c) At location $P_{3}$

Fig. 11 Comparison of dissipation curves at location $P_{7}$

Fig. 12 Measured dissipation curves of $P_{4}, P_{5}$, and $P_{6}$ of Case 4

Fig. 13 Comparison of estimated values of $c_{h}$ and measured values of $c_{v}$

Fig. 14 Comparison of back-fitted and estimated values of $c_{h}$ 


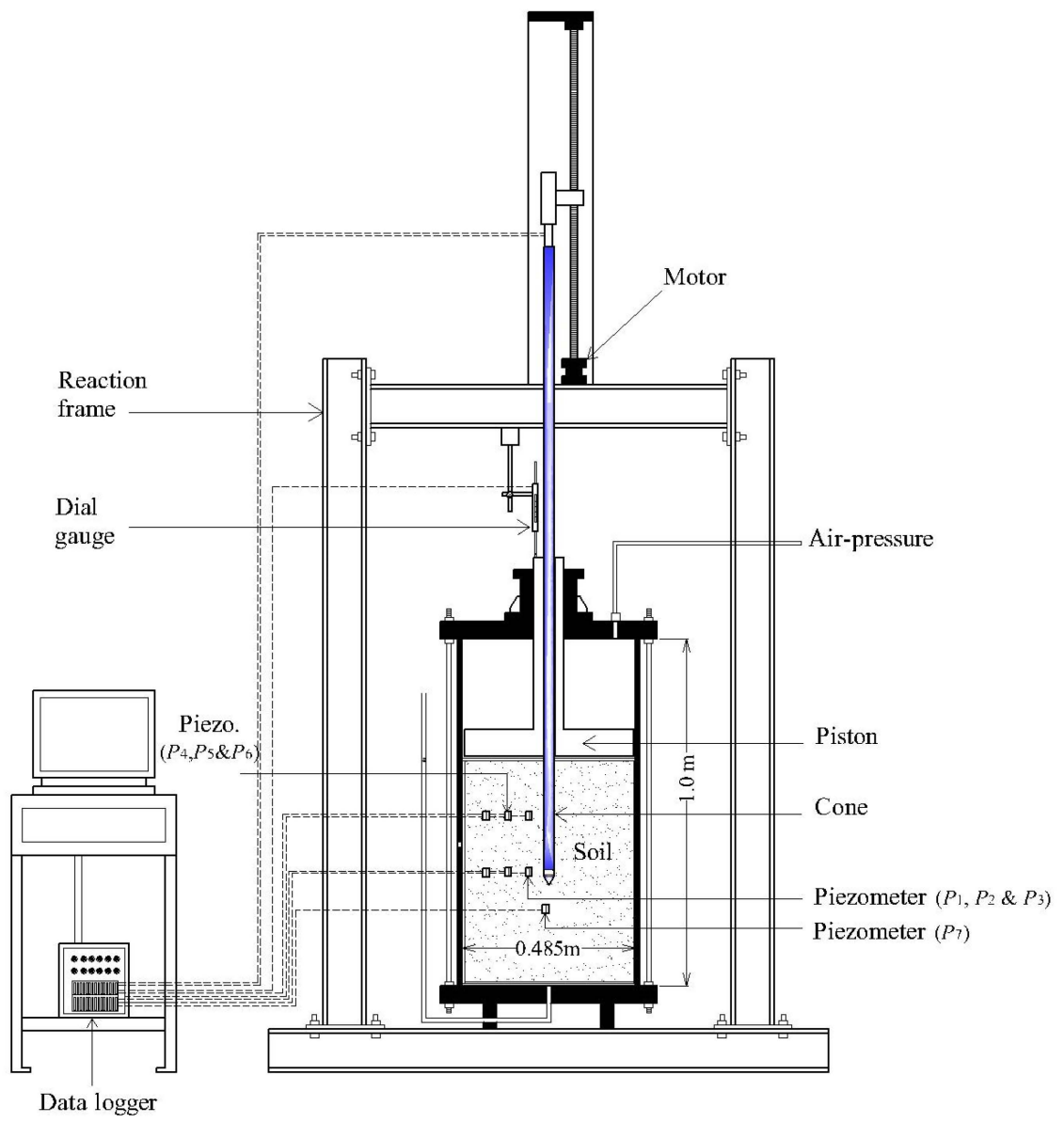

(a) Illustration of the set-up of the test

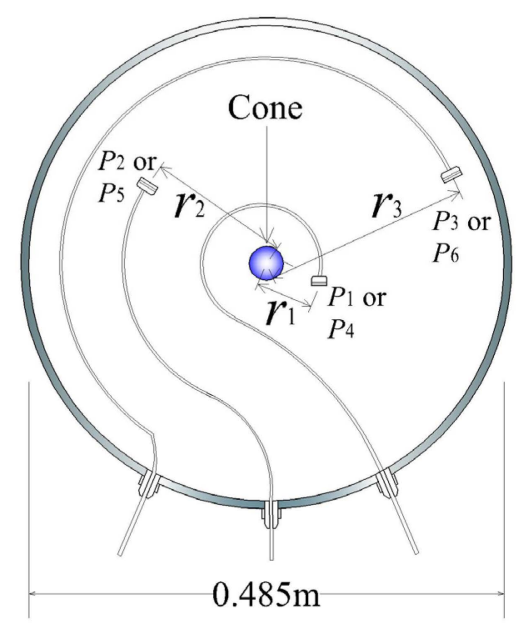

(b) Plan view of the locations of piezometers $\left(P_{1}\right.$ to $\left.P_{6}\right)$

Fig. 1 Schematic diagram of laboratory model test 


\section{Cylindrical}

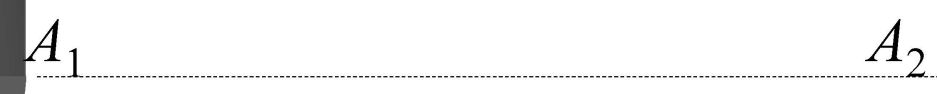

Spherical

Fig. 2 Model for cone penetration induced ground deformation 


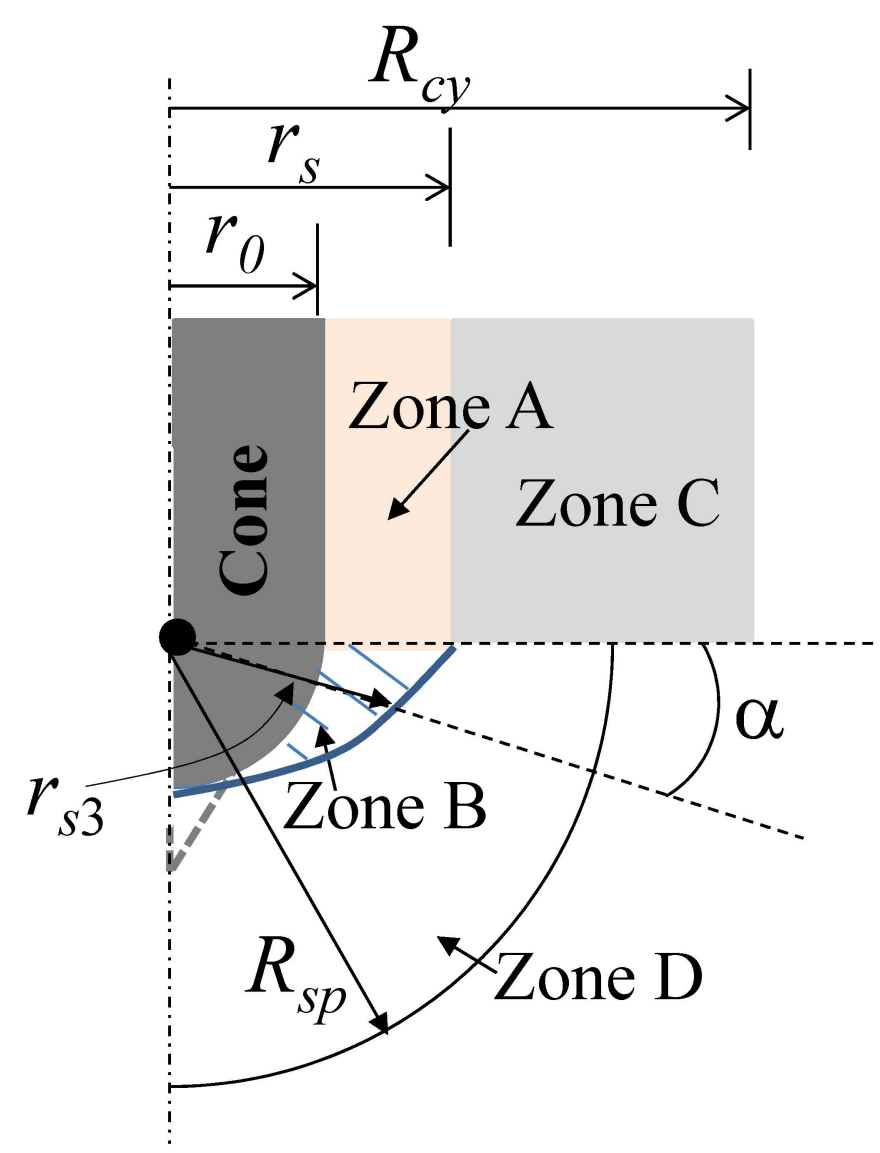

Fig. 3 Zones around the cone 


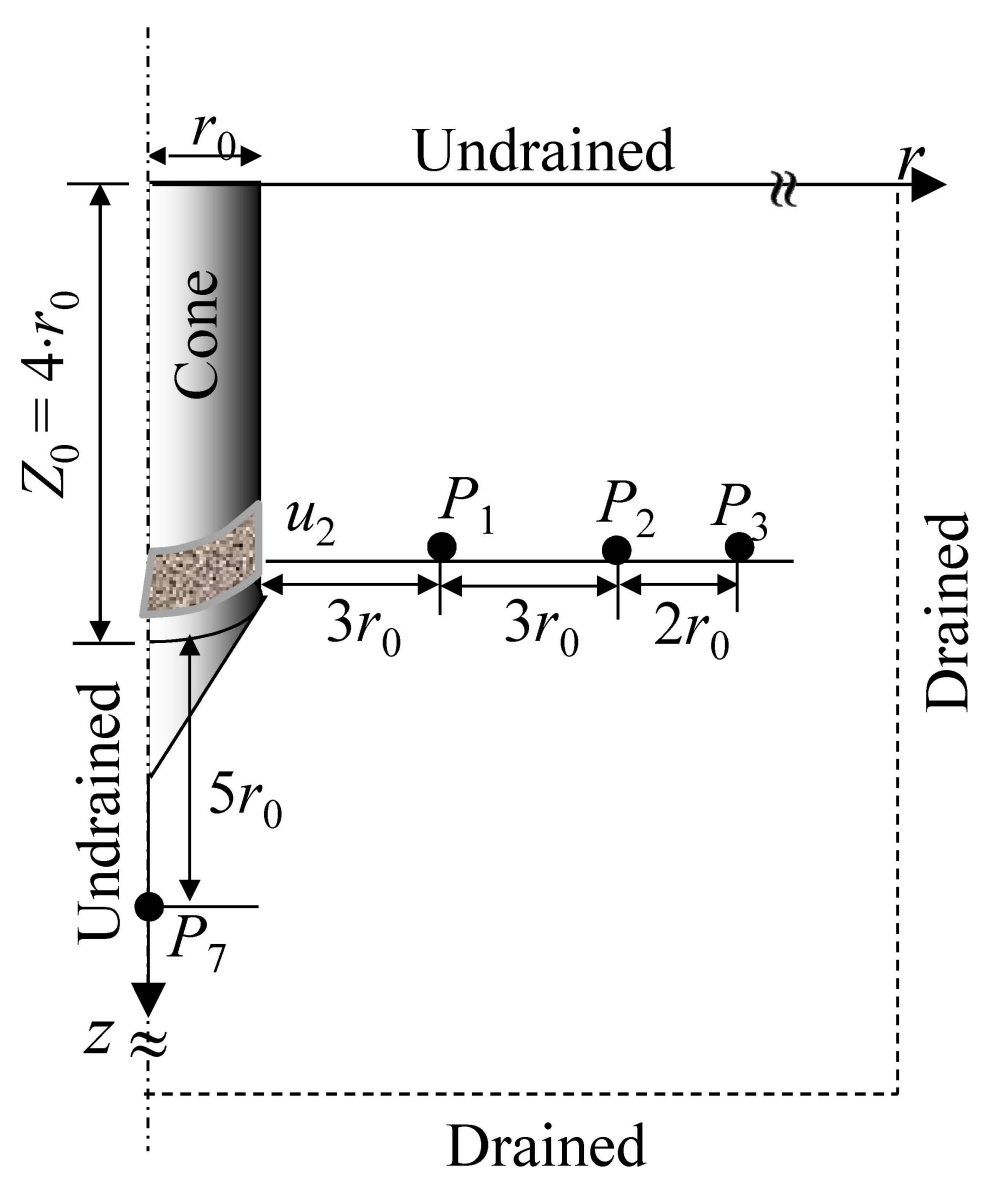

Fig. 4 Model for dissipation analysis 


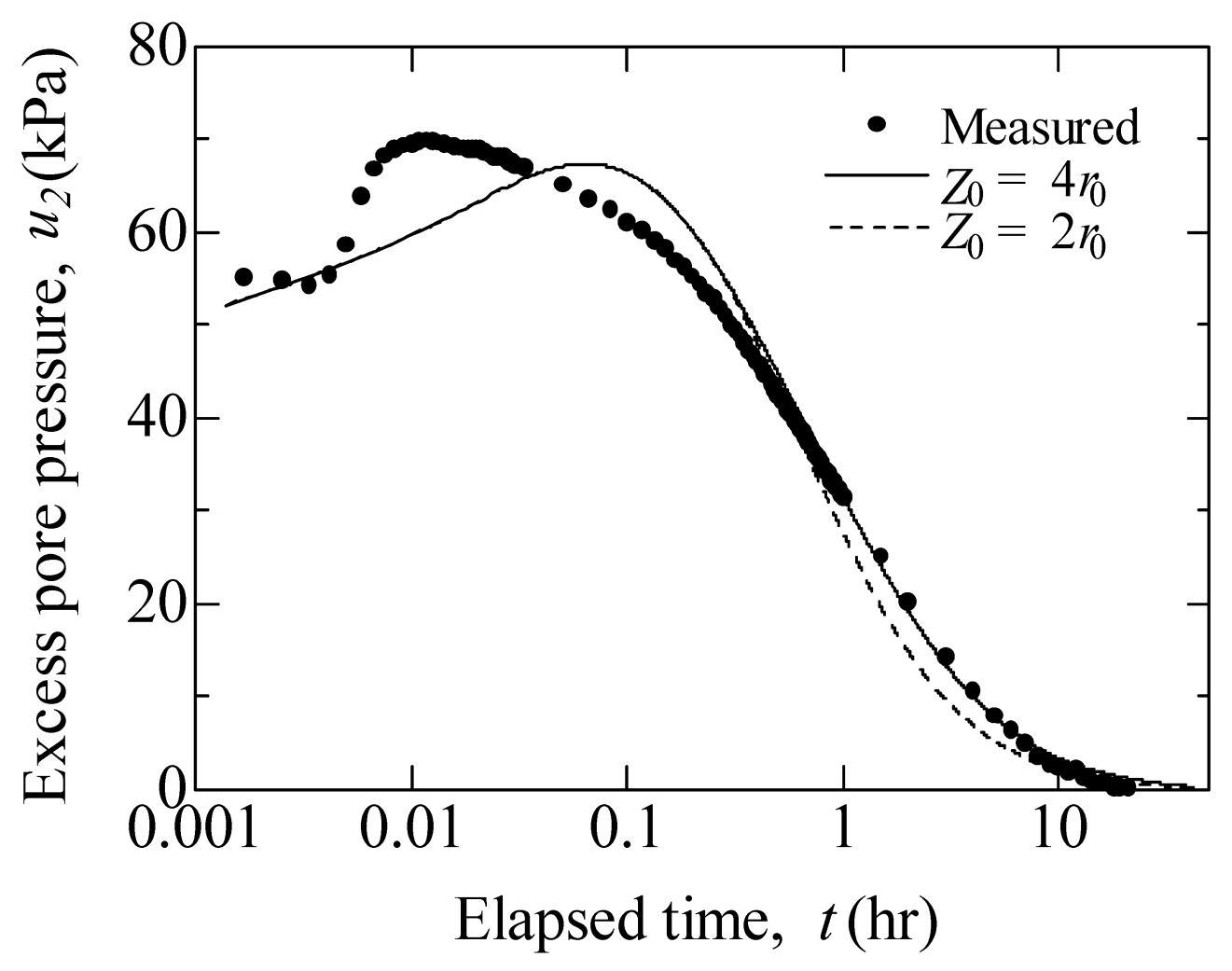

Fig. 5 Effect of $Z_{0}$ on the simulated dissipation curves 


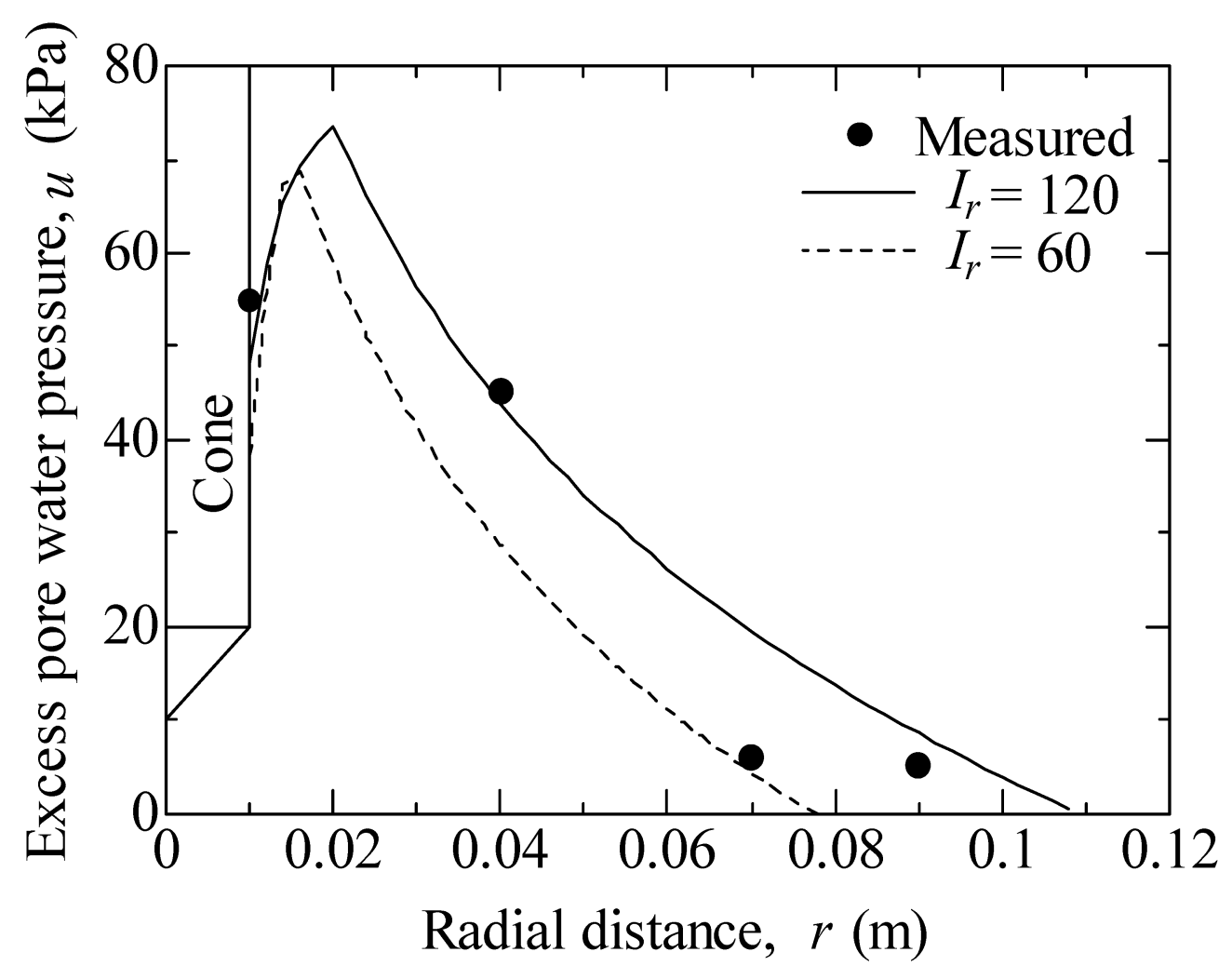

Fig. 6 Effect of $I_{r}$ on the initial $u$ distributions of Case 4 


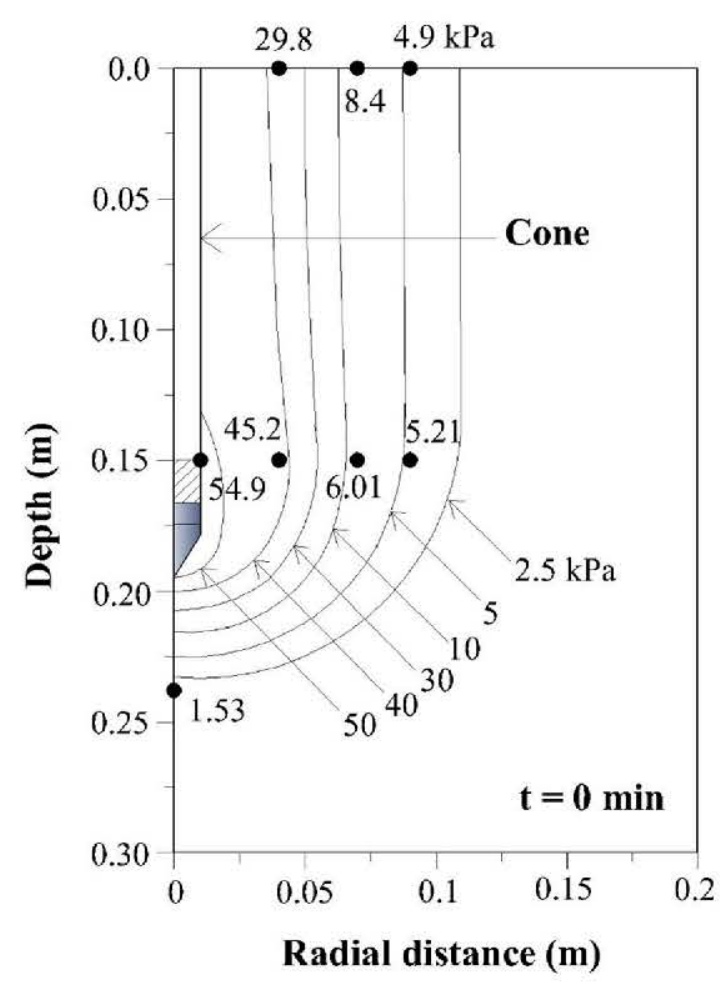

(a) $t=0 \mathrm{~min}$.

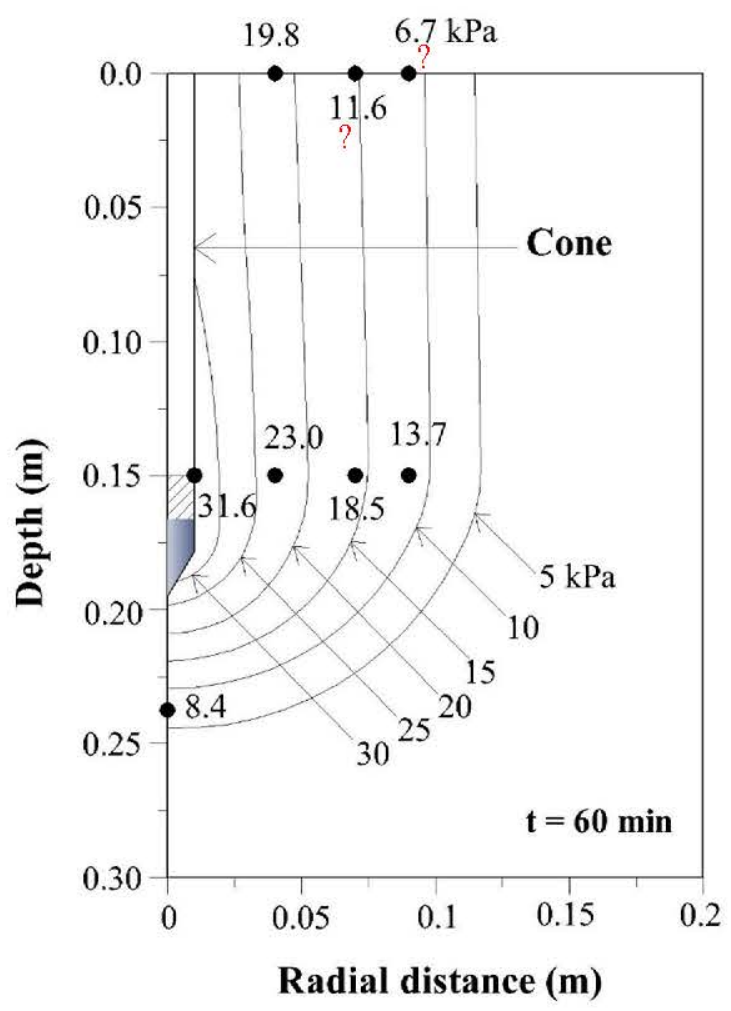

(b) $t=60 \mathrm{~min}$.

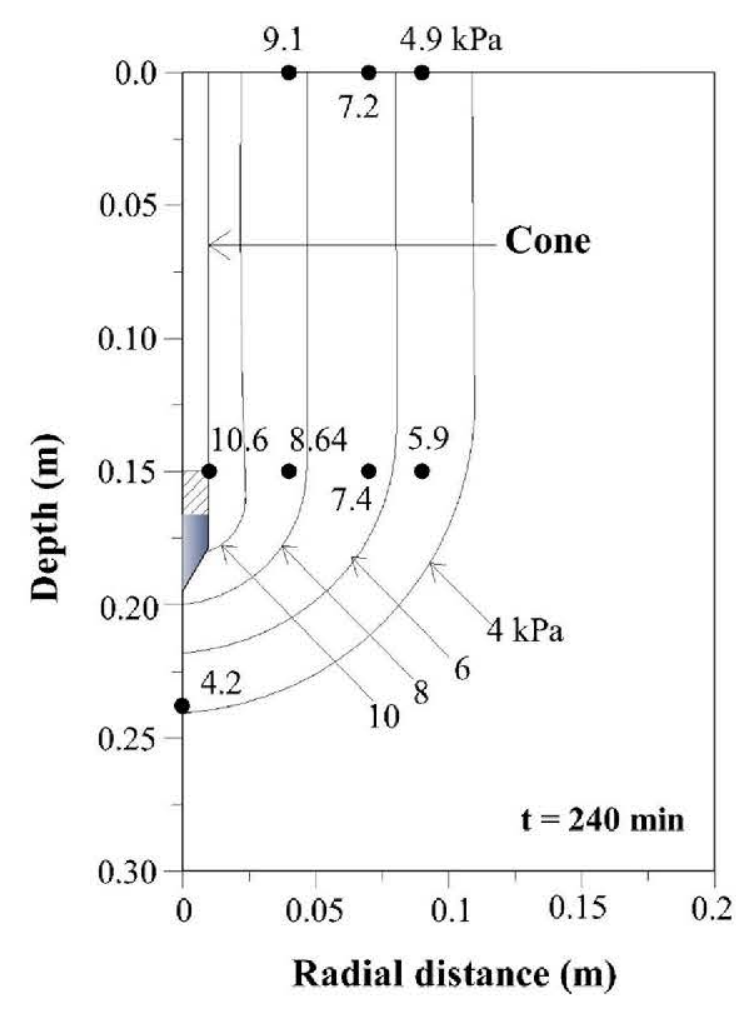

(c) $t=240 \mathrm{~min}$.

Fig. 7 Measured excess pore water pressure distributions (Case 4) 


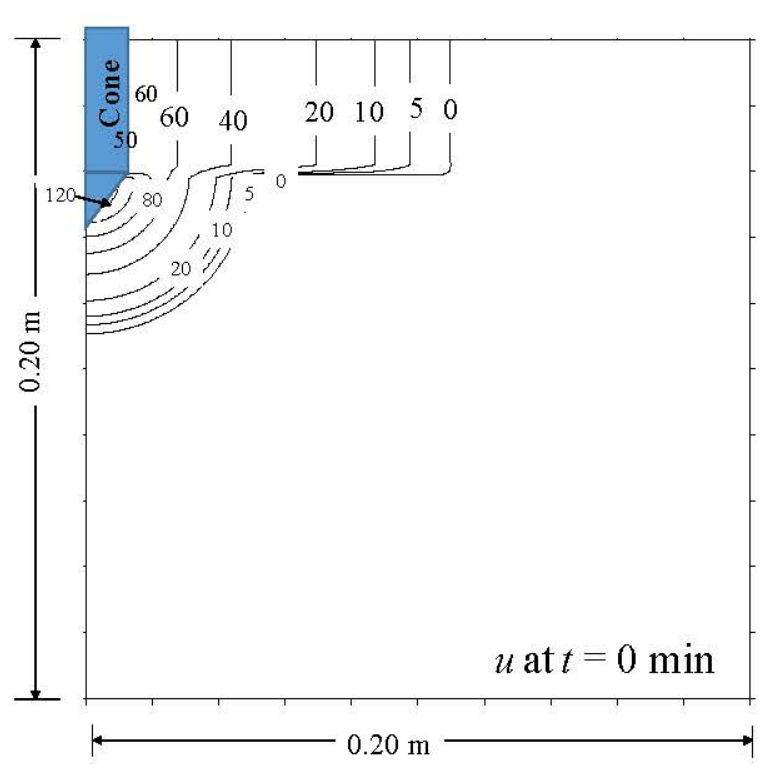

(a) $t=0 \mathrm{~min}$.

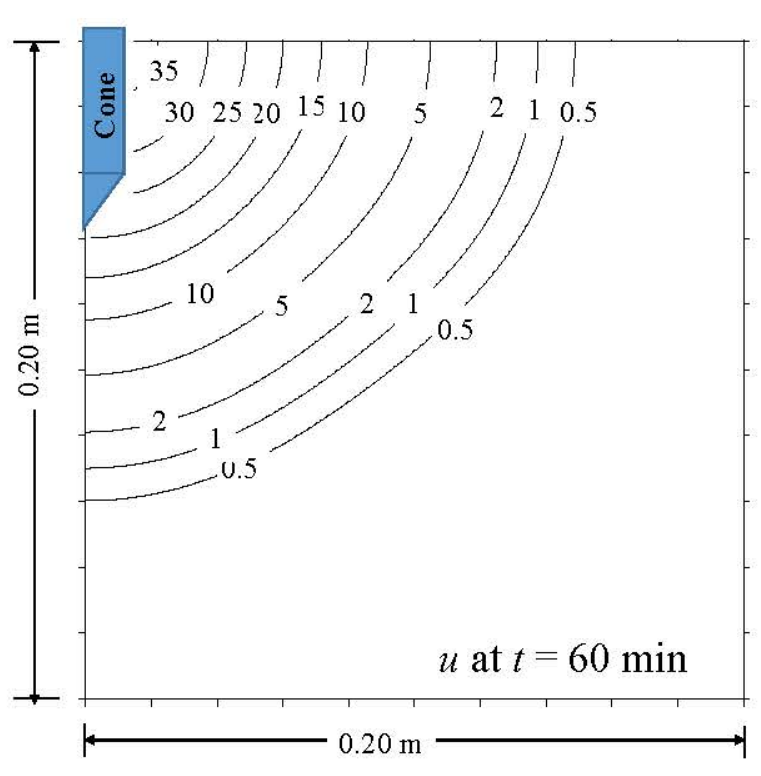

(b) $t=60 \mathrm{~min}$.

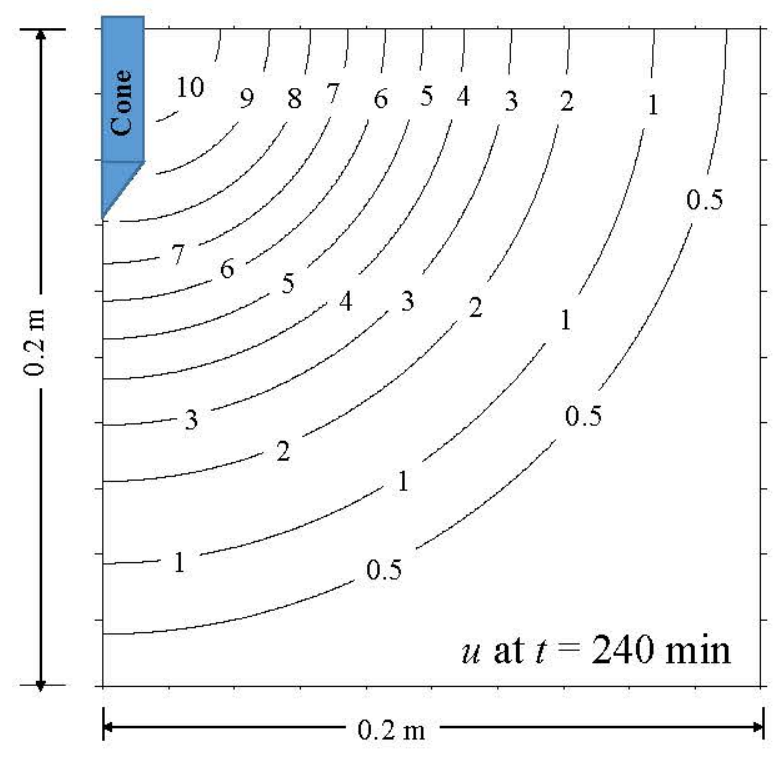

(c) $t=240 \mathrm{~min}$.

Fig. 8 Predicted excess pore water pressure distributions (Case 4) 


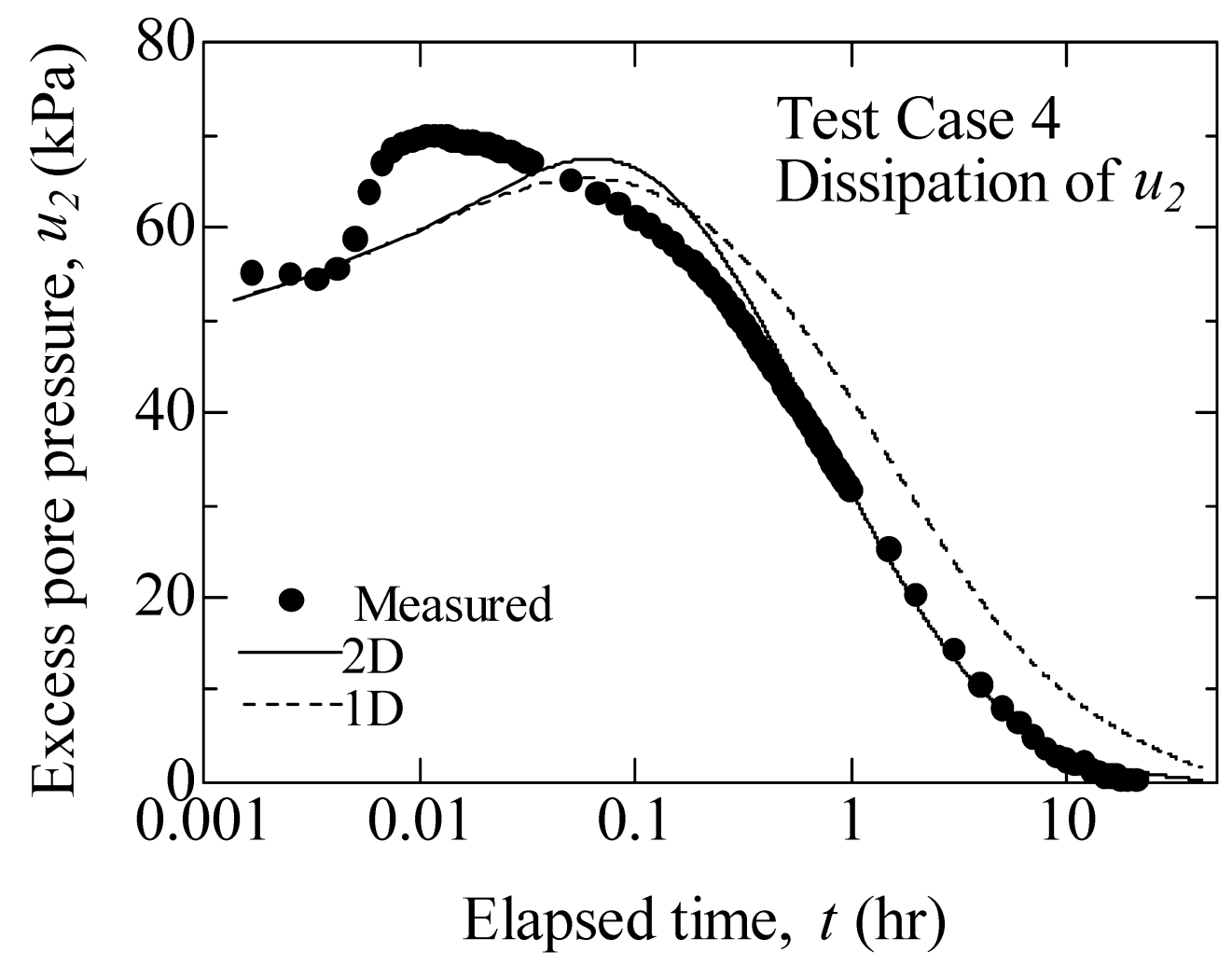

Fig. 9 Comparison of dissipation curves at $u_{2}$ location 


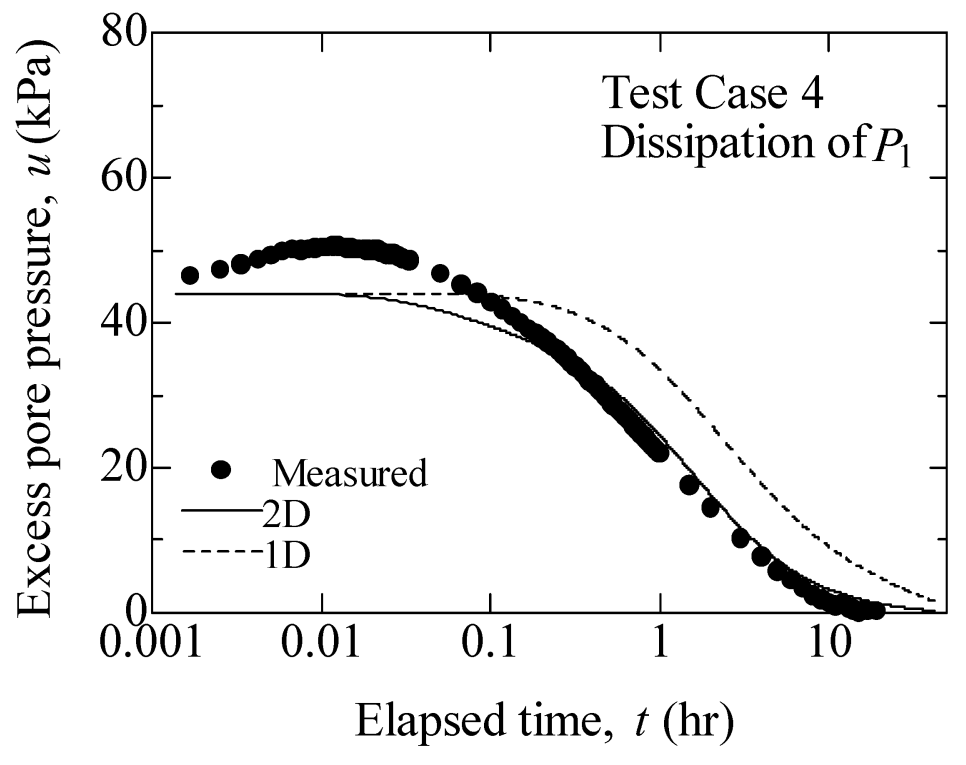

(a) At location $P_{1}$

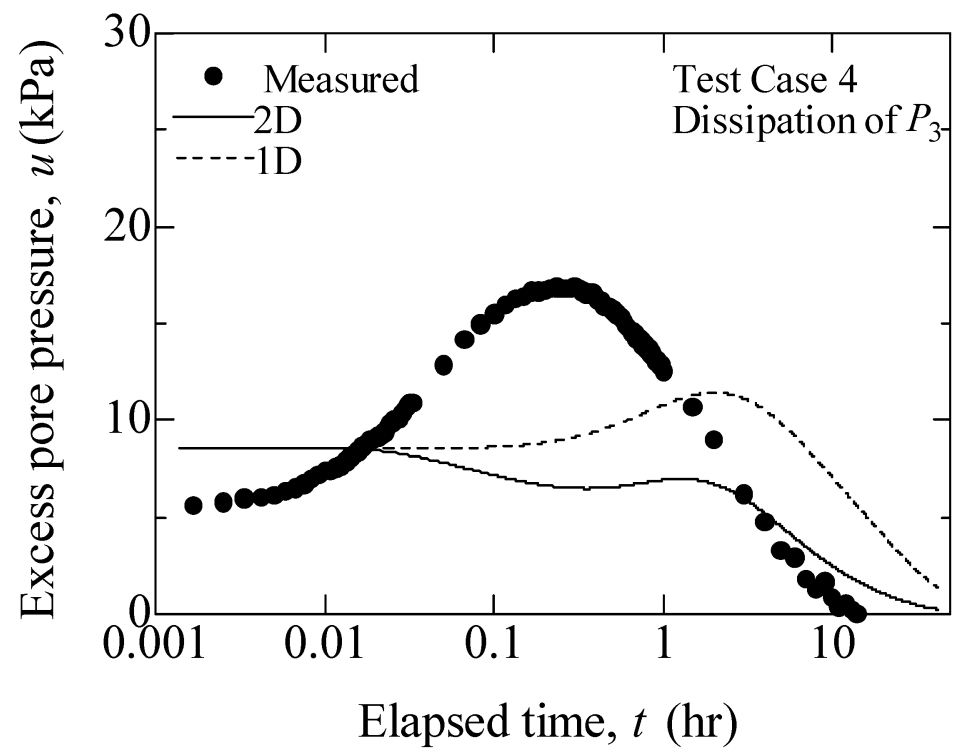

(c) At location $P_{3}$

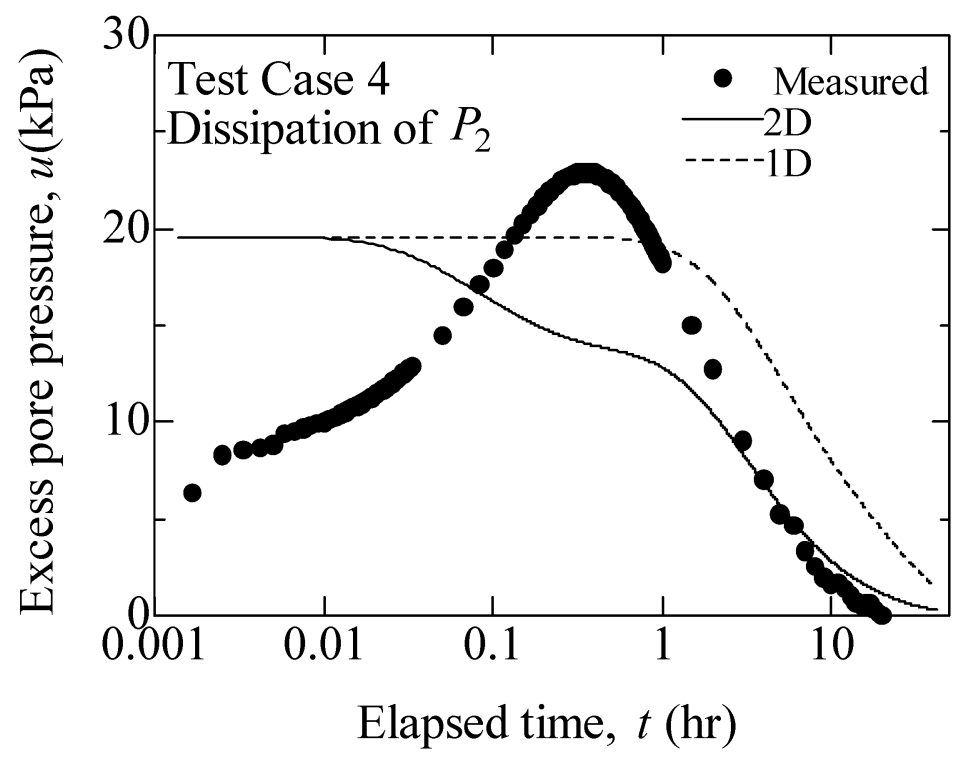

(b) At location $P_{2}$

Fig. 10 Dissipation curves at locations $P_{1}, P_{2}$ and $P_{3}$ 


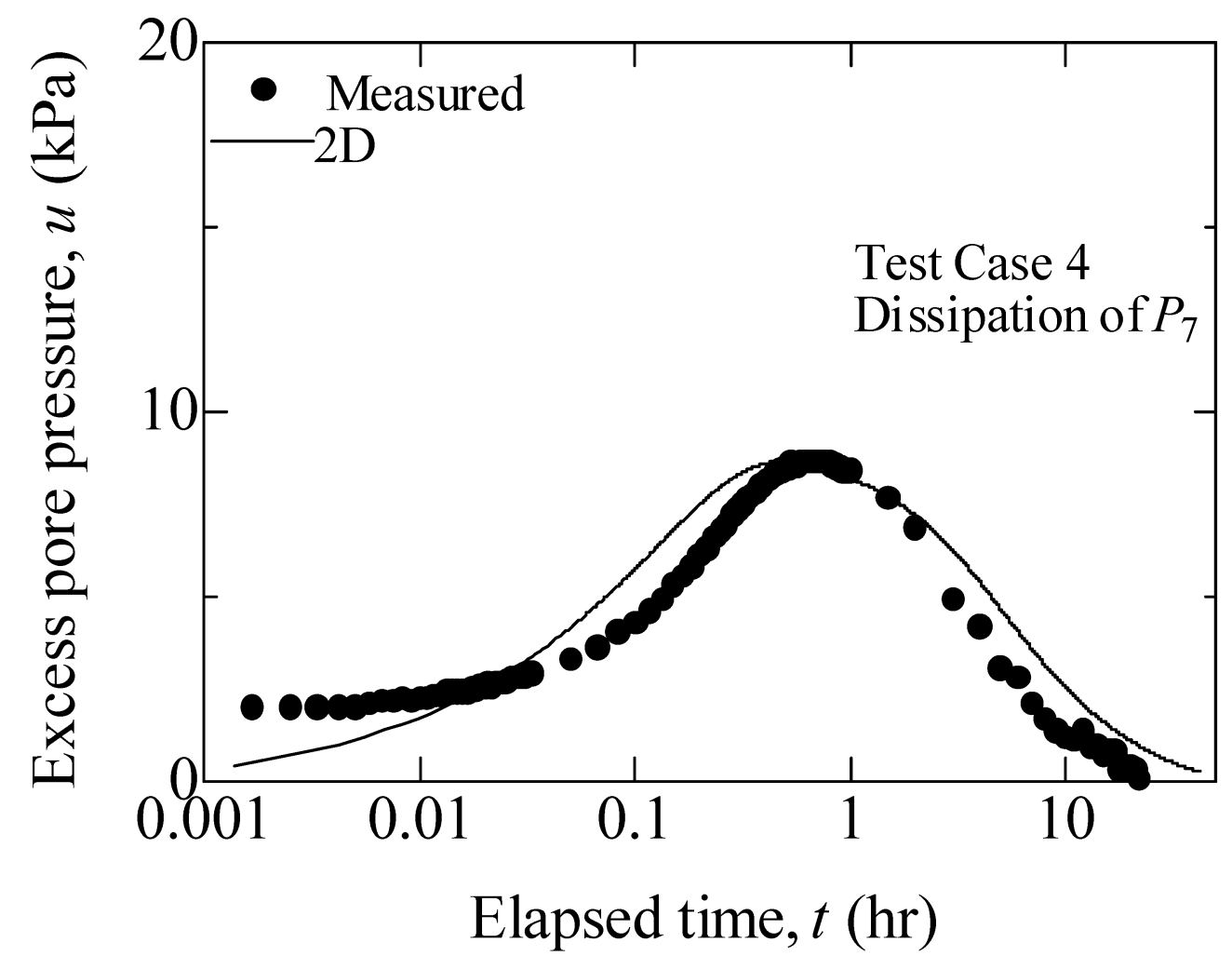

Fig. 11 Comparison of dissipation curves at location $P_{7}$ 


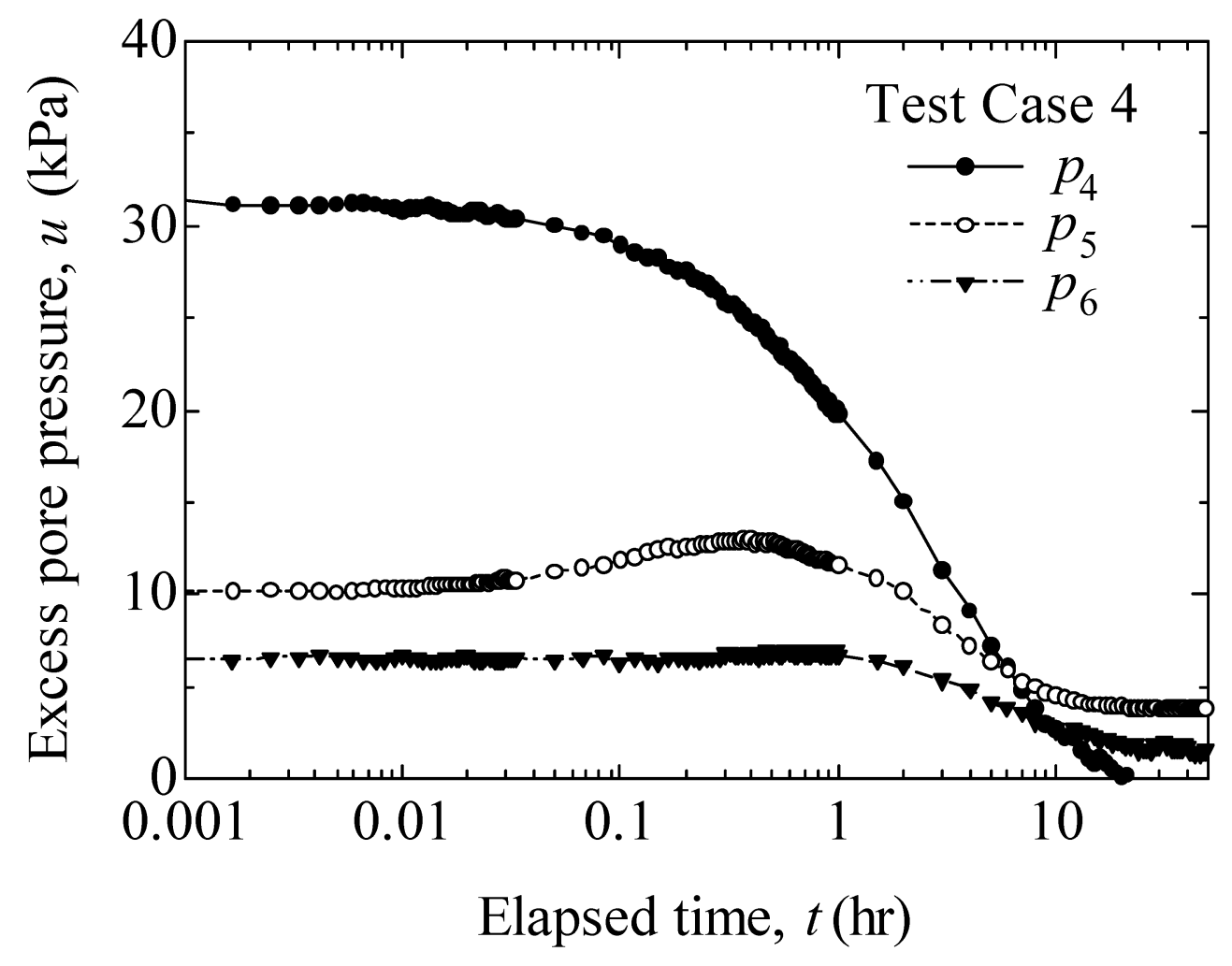

Fig. 12 Measured dissipation curves of $P_{4}, P_{5}$, and $P_{6}$ of Case 4 


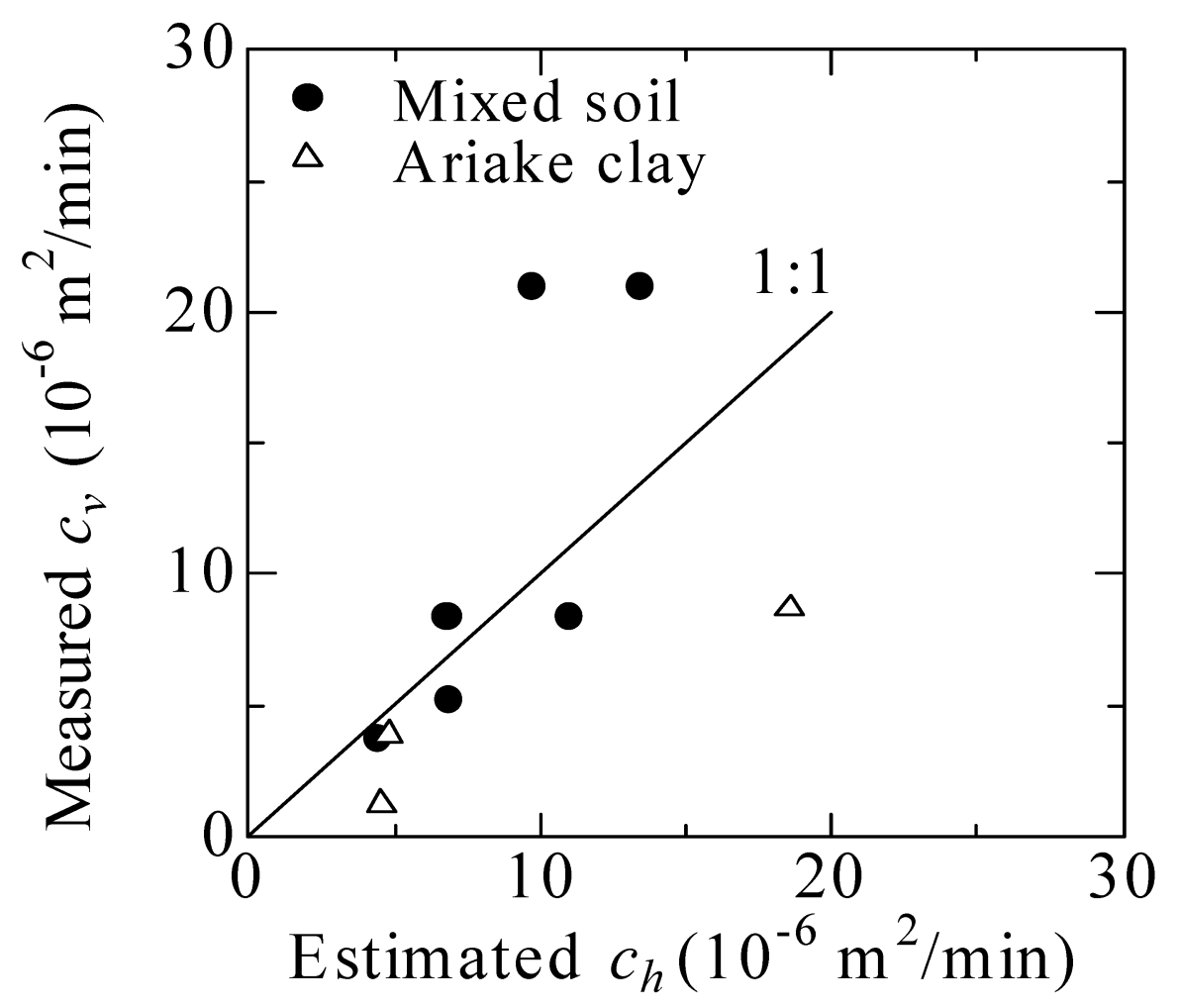

Fig. 13 Comparison of estimated values of $c_{h}$ and measured values of $c_{v}$ 


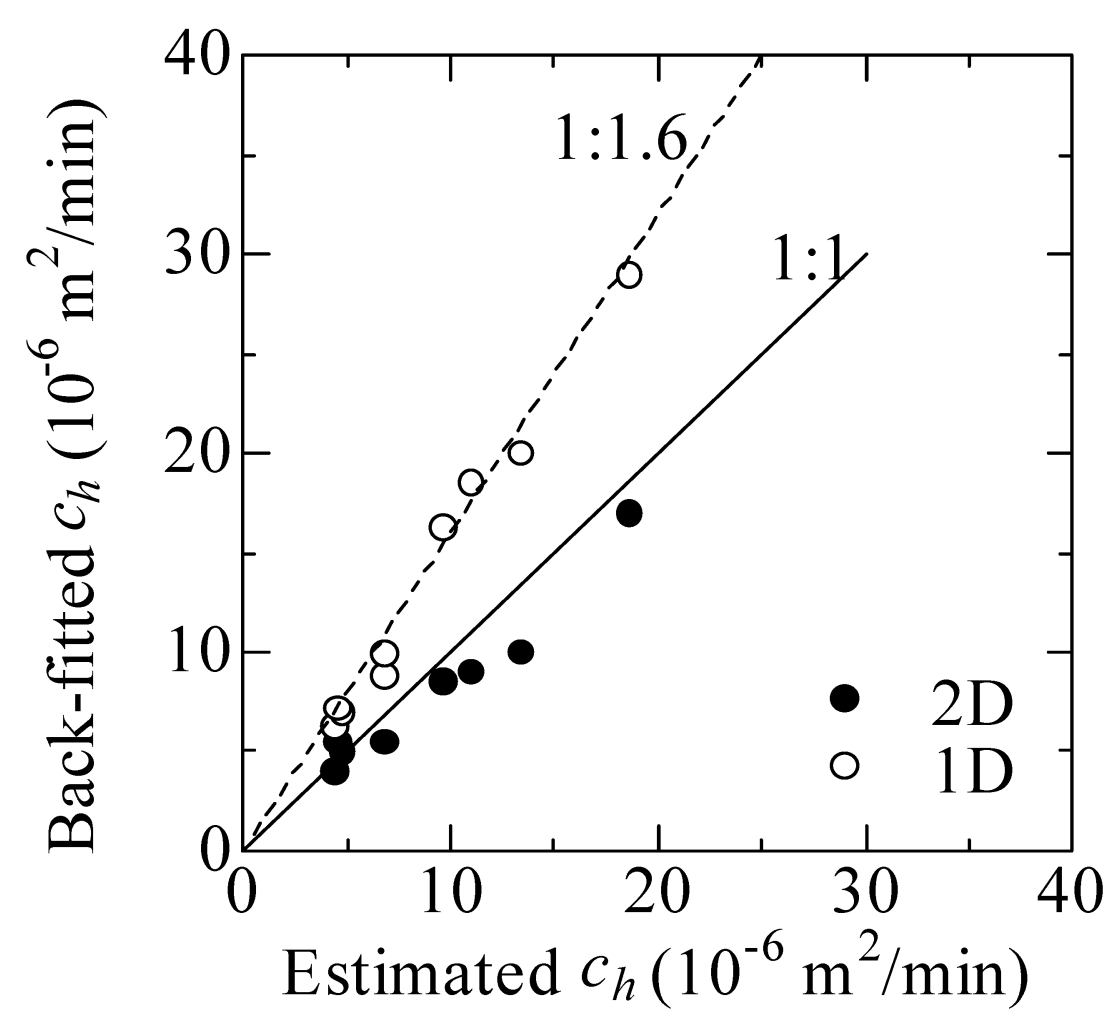

Fig. 14 Comparison of back-fitted and estimated values of $c_{h}$ 


\section{List of Tables}

Table 1 Physical properties of the soils used

Table 2 Cases tested and conditions

Table 3 Estimates of the coefficient of consolidation $\left(c_{h}\right)$ from dissipation test results 
Table 1 Physical properties of the soils used

\begin{tabular}{cccccc}
\hline Soil & $\begin{array}{c}\text { Liquid limit } \\
\text { LL }(\%)\end{array}$ & $\begin{array}{c}\text { Plastic limit } \\
\text { PL }(\%)\end{array}$ & $\begin{array}{c}\text { Finer than } \\
2 \mu \mathrm{m}(\%)\end{array}$ & $\begin{array}{c}\text { Water content } \\
W_{n}(\%)\end{array}$ & $\begin{array}{c}\text { Specific } \\
\text { gravity } \rho_{s}\end{array}$ \\
\hline Ariake clay & 114.0 & 60.6 & 63.5 & 133.0 & 2.65 \\
\hline Mixed soil & 44.24 & 21.28 & 25.0 & 53.1 & 2.63 \\
\hline
\end{tabular}

Table 2 Cases tested and conditions

\begin{tabular}{cccccccccc}
\hline $\begin{array}{c}\text { Test } \\
\text { Cases }\end{array}$ & $\begin{array}{c}\text { Type of } \\
\text { Soil }\end{array}$ & $\begin{array}{c}\sigma_{\mathrm{vm}}^{\prime} \\
(\mathrm{kPa})\end{array}$ & $\begin{array}{c}\sigma_{\mathrm{v} 0}^{\prime} \\
(\mathrm{kPa})\end{array}$ & OCR & $\begin{array}{c}S_{\mathrm{u}} \\
(\mathrm{kPa})\end{array}$ & $I_{\mathrm{r}}$ & \multicolumn{3}{c}{$\begin{array}{c}\text { Locations of } \\
\text { piezometer }(\mathrm{mm})\end{array}$} \\
\hline 1 & Mixed & 96 & 96 & 1 & 29.8 & 120 & 30 & 60 & 90 \\
2 & soil & 96 & 48 & 2 & 26.8 & 120 & 40 & 70 & 90 \\
3 & & 96 & 24 & 4 & 24.2 & 120 & 30 & 60 & 90 \\
4 & & 96 & 12 & 8 & 21.8 & 120 & 40 & 70 & 90 \\
5 & & 48 & 48 & 1 & 14.9 & 100 & 40 & 70 & 90 \\
6 & & 192 & 48 & 4 & 48.3 & 140 & 40 & 70 & 90 \\
\hline 7 & Ariake & 48 & 48 & 1 & 14.9 & 80 & 40 & 70 & 90 \\
8 & clay & 192 & 48 & 4 & 48.3 & 120 & 40 & 70 & 90 \\
9 & & 24 & 24 & 1 & 7.4 & 60 & 40 & 70 & 90 \\
\hline
\end{tabular}

Note: $\sigma_{\mathrm{vm}}^{\prime}$ is the maximum vertical consolidation stress, $\sigma_{\mathrm{v} 0}^{\prime}$ is the initial vertical effective stress in the model ground during piezocone penetration and dissipation tests, $s_{\mathrm{u}}$ is the estimated undrained shear strength, and $I_{r}$ is the rigidity index of the soil. 
Table 3 Estimates of the coefficient of consolidation $\left(c_{h}\right)$ from dissipation test results

\begin{tabular}{|c|c|c|c|c|c|c|c|c|}
\hline \multirow[t]{2}{*}{ Case } & \multirow[t]{2}{*}{ Soil } & \multirow[t]{2}{*}{$t_{\text {min }}^{{ }^{*}}$} & \multirow[t]{2}{*}{$\begin{array}{c}t_{50} \\
\min \end{array}$} & \multirow[t]{2}{*}{$\begin{array}{l}t_{50 c} \\
\min \end{array}$} & \multirow{2}{*}{$\begin{array}{c}\text { Estimated } \\
c_{h} \\
\left(10^{-6}\right) \\
\mathrm{m}^{2} / \mathrm{min}\end{array}$} & \multicolumn{2}{|c|}{$\begin{array}{c}\text { Back fitted } \\
c_{h} \\
\left(10^{-6}\right) \mathrm{m}^{2} / \mathrm{min}\end{array}$} & \multirow{2}{*}{$\begin{array}{c}\text { Measured } \\
c_{v} \\
\left(10^{-6}\right) \\
\mathrm{m}^{2} / \mathrm{min}\end{array}$} \\
\hline & & & & & & $2 \mathrm{D}$ & $1 \mathrm{D}$ & \\
\hline 1 & \multirow{7}{*}{$\begin{array}{c}\text { Mixed } \\
\text { soil }\end{array}$} & 0.45 & 62.37 & 39.4 & 6.81 & 5.5 & 8.8 & 8.40 \\
\hline 2 & & 0.30 & 57.43 & 39.08 & 6.87 & 5.5 & 9.9 & 5.22 \\
\hline 3 & & 1.50 & 63.48 & 27.71 & 9.69 & 8.5 & 16.3 & 21.0 \\
\hline 4 & & 0.70 & 47.44 & 24.43 & 11.0 & 9.0 & 18.5 & 8.40 \\
\hline 5 & & 0.35 & 77.43 & 55.17 & 4.44 & 4.0 & 6.3 & 3.78 \\
\hline 6 & & 1.00 & 48.32 & 21.6 & 13.4 & 10.0 & 20.0 & 21.0 \\
\hline 7 & & 1.35 & 85.24 & 45.48 & 4.82 & 5.0 & 7.0 & 3.90 \\
\hline 8 & \multirow{2}{*}{$\begin{array}{l}\text { Ariake } \\
\text { clay }\end{array}$} & 1.75 & 41.71 & 14.4 & 18.6 & 17.0 & 29.0 & 8.7 \\
\hline 9 & & 0.5 & 62.75 & 41.7 & 4.56 & 5.5 & 7.2 & 1.29 \\
\hline
\end{tabular}

*Note: $t_{\text {umax }}=$ time period from the start of a dissipation test to when the measured value of $u_{2}$ reaches its maximum; $t_{50 \mathrm{c}}=$ corrected time for the excess pore water pressure to dissipate from its maximum value to $50 \%$ of the maximum value. 